\title{
LA FRONTERA DEL GÓTICO: JAMES FERGUSSON Y LA ARQUITECTURA ESPAÑOLA
}

Matilde Mateo

Syracuse University

\section{RESUMEN}

Las historias del arte generales escritas por historiadores anglosajones presentan un mapa de la arquitectura gótica en el que España brilla por su ausencia. En este artículo se indaga cómo, cuándo y porqué se inicio esta tradición de marginación del gótico español, concluyendo que se remonta al historiador de la arquitectura victoriano James Fergusson. Por una parte, Fergusson argumentó que los edificios españoles eran imitaciones imperfectas de modelos europeos, y por otra que los españoles eran una raza semítica carente de genio artístico e incapaz de crear una arquitectura de valor. Estos argumentos de tipo formal y etnológico le llevaron a concluir que la frontera sur del gótico acababa en los Pirineos y debería excluir España. A un nivel más profundo, sin embargo, lo que de verdad se estaba cuestionando no era el mapa del gótico, sino el de la Europa occidental, y si España merecía ser incluído en él.

Palabras clave: J. Fergusson, G.E. Street, Mudéjar, Gótico, Historiografía

\section{ABSTRACT}

The surveys of art history written by anglophone scholars picture a map of the Gothic architecture that leaves Spain out. This paper inquiries into when, how and why this marginalization begun, tracing it back to the Victorian historian of architecture James Fergusson. On the one hand, Fergusson argued that the Spanish monuments were imperfect imitations of European models. On the other hand, he claimed that the Spaniards were a semitic race, lacking artistic genius and unable to create any architecture of worth. These formal and ethnological arguments led him to conclude that the southern border of the map of Gothic architecture should end at the Pyrenees and exclude Spain. At a deeper level, however, what was really at stake was not the extension of the map of the gothic, but of Western Europe, and whether Spain deserved to be included in it.

Keywords: J. Fergusson, G.E. Street, Mudejar, Gothic, Historiography

Uno de los ejemplos más llamativos de la subjetividad inherente a la práctica historiográfica es el diferente tratamiento de la arquitectura gótica española por parte de historiadores anglosajones e hispanos. Mientras la historiografía española, como es de esperar, presta gran atención a nuestras catedrales, iglesias, monasterios, palacios y castillos góticos, la británica y norteamericana suelen ignorarlos, especialmente en las historias de carácter generalista. Literalmente, es como si España no poseyese ningún monumento gótico, tal y como puede observarse en mapas ilustrativos de la arquitectura medieval, como por ejemplo el incluido en Janson's History of Art: The Western Tradition (Fig. 1), uno de los manuales de historia del arte más populares en inglés. ' Esta situación se repite con frecuencia en los manuales de historia del arte general, en los de historia de la arquitectura e incluso en los de historia del arte medieval. ${ }^{2}$ Es una omisión particularmente inexplicable dado el interés constante en los monumentos islámicos $y$, aunque no en tan alta medida, los románicos, tales como la mezquita de Córdoba, la Alhambra o la catedral de Santiago. Si bien es cierto que los manuales no son indicadores fiables del estado de conocimiento del gótico español entre los especialistas de habla inglesa, no hay duda de que son 


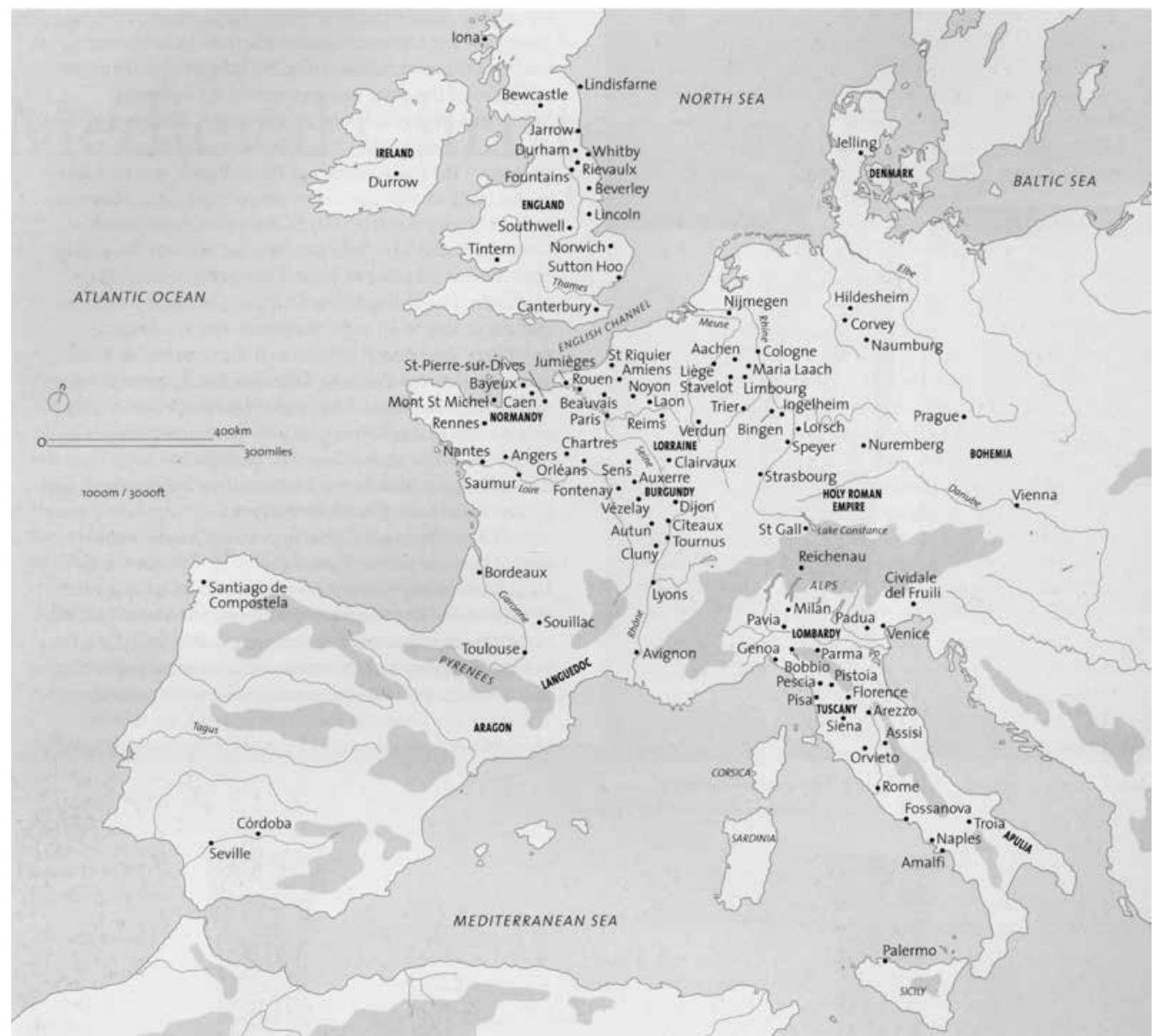

Fig. 1. Mapa de Europa en la Edad Media (Davies, Penelope J.E., Denny, Walter B., Hofrichter, Frima F., Jacobs, Joseph F., Roberts, Ann S., Simor, David L., Janson's History of Art: Western Tradition, $7^{\text {a }}$ edición, 2007. Reproducido con permiso de Pearson Education, Inc., New York).

sintomáticos del interés que éste despierta a un nivel más general o popular, y de que no sólo reflejan su falta de prestigio sino que también contribuyen a perpetuarlo. Al fin y al cabo, los manuales son los que establecen el canon de las obras maestras y los paradigmas estilísticos, los que introducen el estudiante universitario y el aficcionado a la disciplina, y los bestsellers indiscutibles de la historiografía artística.

Por experiencia personal, la realidad es que los amantes de la arquitectura gótica en Gran Bretaña, y aún más marcadamente en Norteamérica, no suelen considerar España como un lugar de destino, que los cursos universitarios sobre gótico español son prácticamente inexis- tentes, y que los especialistas en el tema son una reducida minoría en el ámbito de los estudios medievales. Igualmente, mientras el número de libros dedicados al gótico francés o inglés es considerable, el de los dedicados al gótico español es prácticamente insignificante. Sólo hay una historia de la arquitectura gótica española en inglés, Some Account of Gothic Architecture in Spain (1865) de G. E. Street, a la que hay que sumar los estudios más restringidos de los norteamericanos G.G. King, Mudéjar (1927) y R.A. Cram, The Cathedral of Palma de Mallorca (1932). ${ }^{3}$ La antigüedad de dichos estudios, su limitado número y la falta de continuadores son más que elocuentes y revelan la existencia de 
una tradición historiográfica que ha continuado perpetuándose a sí misma sin cuestionar las razones de su propia existencia. A no ser que aceptemos que los edificios españoles no son merecedores de atención, este desinterés se configura como una opción específica y deliberada digna de investigación.

Con el objetivo de entender mejor la mecánica y naturaleza de esta tradición, el presente artículo investiga su origen y propone que ésta se remonta al historiador victoriano James Fergusson (Fig. 2). El mapa del gótico por él trazado respondía, como veremos más adelante, a una ideología y condiciones históricas precisas, en las que la arquitectura era considerada como la manifestación más elocuente y veraz de la identidad nacional, y en las que el estilo gótico se erigía como la insignia indiscutible de la identidad y superioridad europea. Desde este punto de vista, el establecimiento de la frontera del gótico, de su extensión geográfica en Europa, adquirió unas fuertes connotaciones políticas de amplio alcance que determinaron, de hecho, la inclusión o exclusión de un país en Europa, la jerarquía interna de los estados occidentales, y el carácter de las differentes nacionalidades y de

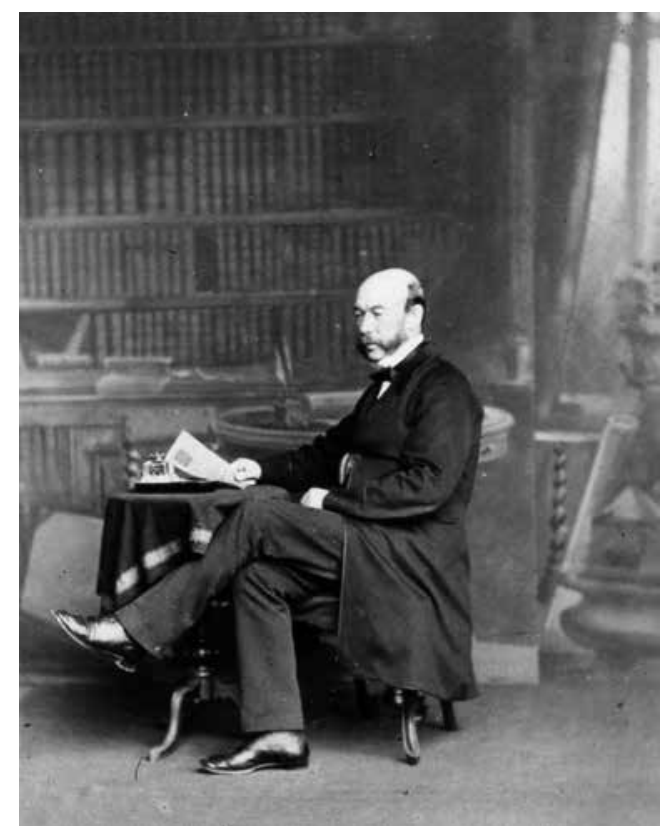

Fig. 2. James Fergusson, con permiso del Royal Institute of British Architects.
Europa misma. Esa frontera, además, como la polisemia del propio término indica, engendró múltiples y contradictorios escenarios en los que España se configuraba como confín del estilo, como un lugar de encuentro entre Occidente y Oriente, así como un territorio inexplorado -frontera científica-, y una area arquitectónicamente infradesarrollada. Fue precisamente el último de estos significados, el de frontera como territorio infradesarrollado ubicado al margen de la civilización, el que más contribuyó a la segregación posterior de los monumentos españoles. Y ese entendimiento del gótico español tuvo su promotor más efectivo en la pionera historia de la arquitectura de Fergusson.

\section{James Fergusson, el Vitruvio del mundo moderno}

A pesar de su importante papel en la marginación del gótico español, James Fergusson (1808-1886) es prácticamente un desconocido en España, lo que no es de extrañar dado que su obra no ha sido traducida nunca al castellano, y que su presencia en las bibliotecas españolas es prácticamente inexistente. ${ }^{4}$ Su prestigio en el mundo anglosajón tampoco ha resistido bien la prueba del tiempo. Pese a su inclusión sistemática en los fondos bibliotecarios norteamericanos y británicos, hoy en día su nombre es sólo familiar en los círculos especializados en la arquitectura india, mientras que su labor historiográfica sigue todavía a la espera de un estudio monográfico que fue reclamado ya hace tiempo por Nikolaus Pevsner. ${ }^{5}$ En vista de su actual olvido, no deja de ser sorprendente que una de sus necrológicas se refiriese a él como "un estudioso de la arquitectura tan importante en el mundo moderno como Vitruvio lo fue en el antiguo». ${ }^{6}$ Aunque el elogio es exagerado, Fergusson fue efectivamente uno de los historiadores de la arquitectura más eminentes de la Inglaterra Victoriana. ${ }^{7}$ Este status venía avalado tanto por su prolífica obra como por la asombrosa versatilidad de sus intereses, los cuales abarcaban desde la historia a la teoría, de Stonehenge a los monumentos de Tierra Santa, pasando por la arquitectura india, las edificaciones militares y los templos griegos, por mencionar sólo algunos de sus estudios. Fue también un hombre controvertido, extremadamente independiente, y con una personalidad 
intransigente, arrogante y provocadora, cuyo desdén explícito por las prácticas revivalistas dominantes por aquel entonces le granjearon una impopularidad considerable; si bien no hasta el punto de eclipsar su extraordinaria reputación erudita. Es significativo que incluso sus detractores se vieron obligados a reconocer la autoridad de "sus magistrales y cuidadosos estudios de todo tipo», y que ésta fuese corroborada por prominentes figuras internacionales, tales como el afamado arqueólogo alemán Schliemann, descubridor de Troya, el cual le dedicó su obra Tyrins, elogiando el «conocimiento del arte»y "genio original» de Fergusson. ${ }^{8}$

La iniciación de Fergusson en la historia de la arquitectura fue bastante anómala y explica, en gran medida, la extraña simbiosis de convencionalismo y originalidad que presidió sus estudios. Fergusson no era un arquitecto profesional ni había recibido una educación como historiador, sino que era un autodidacta cuyo amor por este arte floreció en un lugar poco común, la India, país en el que residió varios años durante su juventud mientras probaba fortuna en los negocios familiares de índigo. Los monumentos del país le fascinaron despertando en él una inesperada y entusiasta vocación por el estudio arquitectónico que terminaría por monopolizar su vida. Los edificios indios, sin embargo, no se prestaban bien a ser juzgados con los criterios de excelencia artística occidentales. Además, carecían de documentación exhaustiva y una tradición historiográfica propia, lo que llevó a Fergusson a desarrollar una metodología ad hoc que resultaría sumamente innovadora e influyente. De especial interés son dos prácticas que introdujo y que se convertirían en básicas para el futuro desarrollo de la disciplina. Una fue el uso extensivo de fotografías, ya que Fergusson primaba la apariencia de los edificios sobre cualquier evidencia documental. La otra fue el empleo de un método comparativo que le permitiese deducir evoluciones y relaciones estilísticas con las que elaborar su historia. Este método, desarrollado para la arquitectura india, fue luego aplicado a otros lugares y períodos, incluído el gótico español, con resultados de gran originalidad.

Lo que más contribuyó a cimentar el prestigio como historiador de Fergusson en su propia época, sin embargo, no fueron sus estudios sobre la arquitectura india, sino su autoría de la primera historia universal de la arquitectura en inglés. Publicada por primera vez en 1855 bajo el título de The Illustrated Handbook of Architecture, esta obra gozó de un éxito inmediato, prolongado en la segunda mitad de siglo por las sucesivas ediciones, revisiones y reimpresiones en Gran Bretaña y Estados Unido, síntoma todas ellas, a su vez, de su estatus como obra de referencia fundamental. ${ }^{9} \mathrm{El}$ proyecto historiográfico en sí era de una ambición extraordinaria tanto por su naturaleza como por los objetivos anhelados. Tal y como confesó en el prefacio de la primera edición, Fergusson quería que su ámbito, metodología y formato superasen al de todas las historias de arquitectura previas -un fin que consiguió en gran medida. No sólo amplió el número de estilos, regiones y períodos acostumbrados, incluyendo, por ejemplo, por primera vez la arquitectura norteamericana, sino que también evitó convertir su historia, como era habitual, en una colección de datos fragmentados e inconexos. En su lugar, Fergusson re-elaboró toda la información por él compilada con el fín de articular todos los estilos y regiones del mundo entorno a un discurso historiográfico único y coherente. $Y$ ésto lo hizo en un estudio con una profundidad y lenguaje que atrajeron tanto al neófito como al especialista, plenamente ilustrado, y en un formato barato y manejable. En otras palabras, Fergusson había inventado lo que en nuestros días consideramos como el manual de historia de la arquitectura. ${ }^{10}$

El hilo de la formidable sinopsis de Fergusson era el progreso de la arquitectura, entendido de una forma unilineal como una acumulación de sucesivas mejoras proporcionadas por las diversas culturas del mundo a lo largo del tiempo. Al igual que sus compatriotas John Ruskin y A.W. Pugin, Fergusson defendía que la excelencia arquitectónica radicaba en «una construcción ornada y ornamental», es decir, en la adecuada combinación de un diseño constructivo sensato y bello, con una decoración de buen gusto. ${ }^{11}$ A diferencia de ellos, sin embargo, Fergusson consideraba la originalidad como un valor esencial $y$, por tanto, despreciaba profundamente cualquier forma de copismo. En su 
opinión, un estilo arquitectónico era producto de unas circunstancias históricas, sociales y culturales concretas, y no podía ser importado a otro milieu sin violencia. La perfección absoluta, argumentaba, era una cualidad inalcanzable, ya que el inexorable avance del tiempo transformaría las condiciones preexistentes, quebrando inevitablemente la perfecta sintonía entre un estilo y su época. El deber de cada generación era tratar de mejorar la arquitectura que les había sido legada por la precedente por medio de soluciones innovadoras que se adaptasen a los nuevos tiempos. La imitación de fórmulas de culturas ajenas o pretéritas, concluía Fergusson, era un contrasentido y una regresión en el progreso de la arquitectura.

La noción de progreso así entendida se convirtió en el marco de referencia esencial con el cual juzgar cada estilo histórico, y dentro de éstos, la producción arquitectónica de cada país. Aunque Fergusson, según sus propias palabras, sólo estaba intentando crear «el mapa general de la arquitectura mundial», implicando la reconstrucción de un rompecabezas en el que todas las piezas tuviesen igual valor dentro de un contexto intrahistórico e internacional, la verdad es que su criterio del progreso arquitectónico introdujo una jerarquía que ubicaba los diferentes estilos y países en rivalidad mutua. ${ }^{12}$ Con respecto a los estilos, Fergusson estableció dos rangos principales, uno inferior, constituido por todos los estilos post-medievales, a los que calificó de «imitativos» o «monkey styles» por su imitación de soluciones previas, y otro claramente superior, el de los estilos «verdaderos», comprendiendo todos los producidos antes del Renacimiento. Fergusson concedió al gótico un lugar de honor entre los «estilos verdaderos» argumentando que su estructura y decoración eran una superación clara de los experimentos clasicistas. ${ }^{13}$ Por su parte, la jerarquía de cada país dentro del gótico, al igual que en otros estilos, era determinada por sus contribuciones originales y se hacía explicita en la organización por capítulos nacionales, la extensión de éstos, y los juicios de valor emitidos por Fergusson. En el caso del gótico, Francia y Gran Bretaña fueron situados a la cabeza, cada uno con más de cien páginas, mientras que España y Portugal merecieron elocuentemente sólo veinticinco.

\section{España, una nueva frontera del gótico}

Es importante resaltar que el interés de Fergusson por el gótico español no era específico sino más bien un producto colateral de lo ambicioso de su proyecto historiográfico, de su intención de incluir en él a todos los países. Su curiosidad por España obedecía a una pregunta muy concreta: ¿en qué medida y forma había contribuído ésta al desarrollo del gótico europeo, $y$, en última instancia, al progreso general de la arquitectura? La respuesta, sin embargo, no era fácil debido a la falta de información sobre el tema, problema que suscitó constantes lamentaciones en la primera edición de su manual de 1855. Ya en el prefacio general de la obra, Fergusson singularizó a España como «casi una tierra incognita para los arquitectos», y un «capítulo en blanco en la historia de la arquitectura cristiana», como se venía denominando al gótico por aquel entonces. ${ }^{14}$ De ello culpaba en gran medida a la popularidad de la Alhambra, objeto de costosas publicaciones en Inglaterra, Francia y España, mientras que las catedrales de Sevilla, Toledo, Burgos y León «carecían de dibujos y mediciones; y los viajeros que se dirijían apresuradamente a la Alhambra, rara vez condescendían a bajarse de sus diligencias para dirigir un mirada de pasada a sus bellezas». ${ }^{15}$ Más adelante, sus capítulos sobre España se iniciaban con una denuncia acerca de lo poco que se sabía del tema aparte de la suposición de que las catedrales eran «numerosas y espléndidas, y que su historia sería de interés supremo». ${ }^{16}$ También protestaba que «con escasas excepciones, no había forma de obtener ni los datos más elementales sobre fechas y estilos de la nobles catedrales medievales de España», ni de «establecer, con ninguna seguridad, cuando se había introducido el estilo apuntado [gótico]». ${ }^{17}$ Por último, y con clara redundancia, el primer subtítulo de la parte dedicada a España escuetamente anunciaba que se trataba de un «Tema imperfectamente conocido». Para exasperación de Fergusson, la España arquitectónica era una tierra inexplora$\mathrm{da}$, desconocida, situada más allá de la frontera del conocimiento de la arquitectura gótica establecido por la historiografía previa.

Lo paradójico, al menos aparentemente, de su frustración es que el tema no era tan imper- 
fectamente conocido como él reclamaba. Había varias publicaciones que contenían considerable información sobre los edificios góticos españoles, tales como la España Sagrada, el Viage de España de Ponz, y las Noticias de los Arquitectos de Llaguno y Ceán. Numerosos compatriotas suyos, tales como Ford, Widdrington, Wells o Hoskins, habían publicado descripciones de los monumentos góticos españoles en sus relatos de viajes. Había también numerosas ilustraciones realizadas por Wells, David Roberts, Villaamil, Laborde, Gailhabaud y Chapuy. ${ }^{18}$ Es más, Fergusson conocía todas estas obras y las había utilizado para su estudio. Su problema pues no era tanto la cantidad de información disponible como su calidad. Ninguna de esas publicaciones tenía en cuenta la integración del gótico español en el contexto europeo. Los autores españoles habían estado satisfechos con el punto de vista local, bien fuese su ciudad, región, o país, y de hecho, a diferencia de otros autores europeos, ninguno había acometido en esa época el estudio de la arquitectura europea o mundial. ${ }^{19} \mathrm{En}$ gran parte de los casos, lo que motivaba el interés de los autores hispanos en los monumentos góticos no era tanto el estilo en sí como orgullo local. ${ }^{20}$ Otro tanto se podría decir de los viajeros extranjeros, quienes generalmente se limitaban a parafrasear a los autores españoles, y cuyo interés en los monumentos góticos radicaba en su ubicación en suelo hispano. ${ }^{21}$ En otras palabras, mientras Fergusson se preguntaba cuál había sido la contribución española al desarrollo del gótico, los eruditos españoles y viajeros británicos adoptaban un punto de vista diametralmente opuesto: ¿cuál había sido la contribución de los monumentos góticos a la gloria local o de España? Además, el interés primordial de Fergusson era comparar efectivamente los edificios españoles y europeos, y para ello necesitaba estudios del gótico español que respondiesen a parámetros similares a los aplicados al gótico francés, inglés, o alemán. En contraste, los estudios a su alcance hacían gala de una metodología obsoleta en la que se primaba la documentación de la cronología, autoría y patronazgo sobre las cuestiones estilísticas y formales. También solían centrarse en edificios individuales más que en discursos históricos coherentes con un amplio alcance temporal o geográfico.
El problema principal radicaba en la ausencia de los documentos que él consideraba esenciales para su labor historiográfica: reproducciones fiables de los edificios. ${ }^{22}$ No había fotografías publicadas de los mismos y las únicas plantas reproducidas por la imprenta eran las de las catedrales de Sevilla, Burgos y León, así como, curiosamente, de las iglesias de S. Millán y los Templarios de Segovia. ${ }^{23}$ Las ilustraciones de los alzados, interiores y exteriores eran más abundantes, pero igualmente inútiles ya que en ellas se sacrificaba la corrección arquitectónica al efecto pintoresco. Acertadamente Fergusson desconfió de los dibujos del pintor escocés David Roberts, pero incomprensiblemente se fió de los de su discípulo, Genaro Pérez Villaamil, cuyos dibujos adolecían de las mismas deformaciones pintorescas que los de su maestro. Como ejemplo baste su ilustración de la Colegiata de Toro (Fig. 3), interpretada como correcta por Fergusson, cuyo cimborrio aparece distorsionado en su verticalidad y forma de los arcos dotándolo de una falsa apariencia gótica. Por su parte, las descripciones de los edificios generalmente se limitaban a alabar la fábrica sin detallar la forma de los arcos, su ubicación y número, el diseño de las cubiertas y alzados, medidas precisas, y otras cuestiones formales de relevancia para Fergusson. Sin información precisa en estos aspectos, no era posible, argumentaba, hacer las distin-

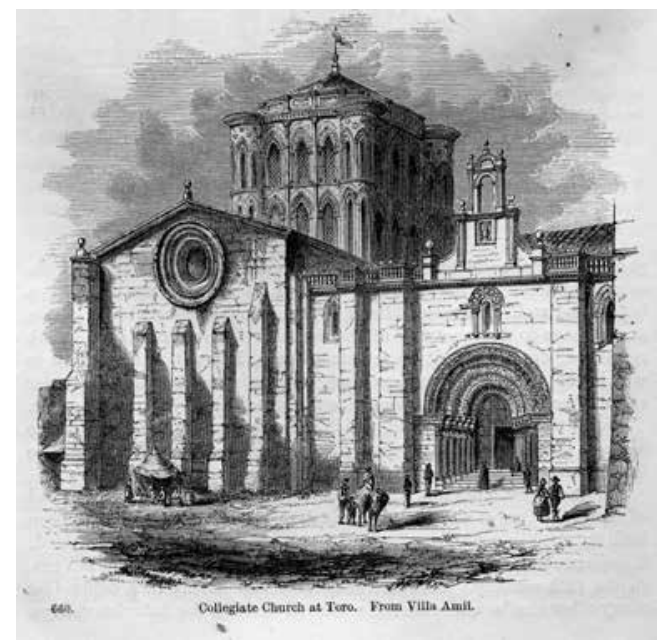

Fig. 3. Colegiata de Toro, copiada de una litografía original de G. Pérez Villaamil. J. Fergusson, An Illustrated Handbook of Architecture, Londres, 1855. 
ciones sutiles propias de la evolución estilística, y se corría el riesgo de llegar a una deducción incorrecta. ${ }^{24}$

En su primer intento de trazar el mapa europeo del gótico, Fergusson descubrió que España era una auténtica nueva frontera historiográfica sin explorar, todavía a la espera de ser sometida a un análisis ordenado, racional y coherente que la pusiese al mismo nivel que Francia, Inglaterra o Alemania. Sus continuos lamentos también contribuían a reforzar su imagen de pionero intrépido, al tiempo que le liberaban de responsabilidad sobre cualquier error que pudiese cometer. Realmente, desde una perspectiva moderna, no deja de asombrar la temeridad de su intento, con información tan imperfecta y sin haber nunca puesto el pié en el país.

\section{La frontera colonizada}

La ignorancia de Fergusson acerca de los edificios españoles no le impidó establecer comparaciones continuas entre éstos y los europeos en su afán por determinar el lugar que España ocupaba en el progreso de la arquitectura europea. En este respecto, la evaluación de monumentos individuales fue en ocasiones muy positiva, rayando a veces en la hipérbole. Por ejemplo, calificó a la catedral de León como «la más elegante y graciosa del mundo». ${ }^{25}$ Afirmó que el perfil de la de Burgos poseía una variedad y riqueza «sin rival en ninguna catedral francesa o alemana, sólo igualado por algunos ejemplos ingleses», mientra declaraba que su fachada occidental «debía de ser una de las compositiones más hermosas en existencia» (Fig. 4). Añadió también que la capilla del Condestable exhibía una riqueza decorativa que superaba incluso a la de la capilla de Enrique VII en Westminster. ${ }^{26}$ La catedral de Sevilla le pareció «tan grandiosa, espaciosa, y tan ricamente decorada, que no había lugar a crítica ante un resultado tan espléndido e imponente». ${ }^{27} \mathrm{El}$ decorativismo de San Juan de los Reyes, en su opinión, «superaba en la riqueza del detalle a la capilla de Enrique VII o la iglesia de Brou», mientras que el de San Miguel de Jerez «sobrepasaba a cualquier otro que se pueda hallar en las catedrales del norte de Europa». ${ }^{28}$ Por último, el claustro de Las Huelgas le cautivó por poseer «una belleza, tanto en

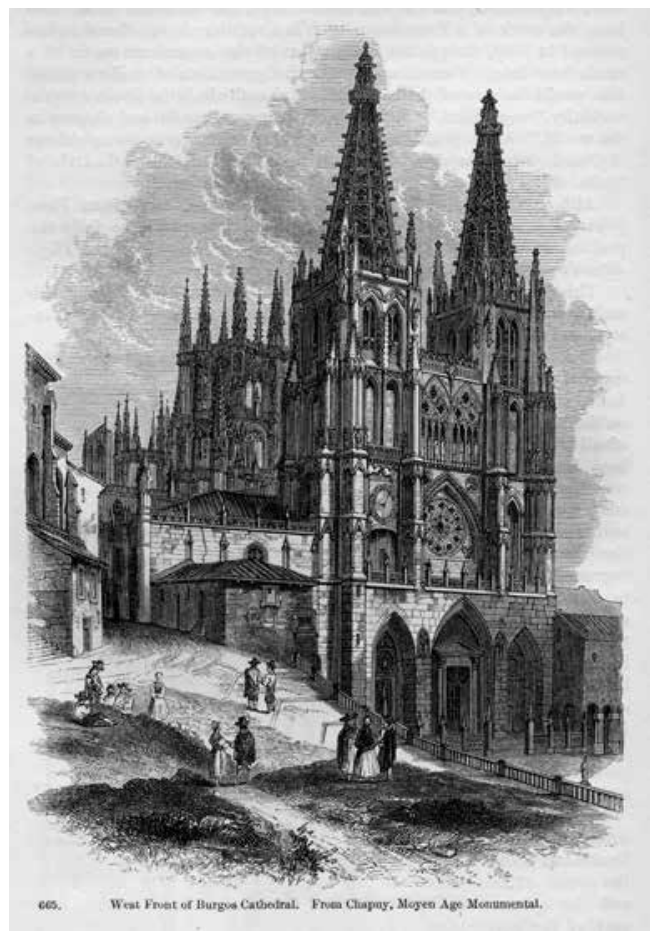

Fig. 4. Fachada occidental de la Catedral de Burgos, tomada de Chapuy. J.Fergusson, An Illustrated Handbook of Architecture, Londres, 1855.

el detalle como en el diseño, sin rival, y quizás no superado por nada de su época y estilo en ninguna parte de Europa». ${ }^{29}$ Excepcionalmente Fergusson incluso admitió que los monumentos españoles pudieron haber servido de modelo a edificios foráneos, como su sugerencia de que la Capilla del Condestable había sido el modelo para la Roslyn Chapel en Escocia -una tremenda concesión para un escocés de nacimiento, como era Fergusson. ${ }^{30}$

Este rosario de elogios, sin embargo, proporciona una impresión falsa. Casi siempre sus alabanzas fueron apostilladas con objecciones, mientras que sus comparaciones estilísticas generalmente derivaron en explicaciones de cómo los edificios españoles se limitaban a importar modelos foráneos apenas comprendidos o alterados. ${ }^{31}$ Así pues, y aunque parezca paradójico, Fergusson invalidó todos sus apasionados encomios de edificios individuales con la conclusión de que en realidad en conjunto no merecían la pena. Pese a esta visión tan desfavorable, con- 
cedió que el gótico español presentaba algunas peculiaridades propias. Una era la ubicación del coro en la nave mayor, la otra, de mucha mayor importancia, era la influencia oriental (islámica) que vió desperdigada por la arquitectura de todo el país. ${ }^{32}$ El quid de la cuestión era si estas peculiaridades podrían ser consideradas como una contribución española al progreso de la arquitectura. Con respecto al coro, el tema quedó zanjado con su dictámen de que era un «absurdo arquitectónico». ${ }^{33}$ Su evaluación del mudéjar -que él denominaba "estilo moresco» y el cual sólo conocía a través de las pintorescas litografías de Villaamil- fue mucho más compleja aunque no menos contradictoria. ${ }^{34}$

Fergusson sentía una fascinación sincera por el mudéjar y lo consideraba como «una de esas

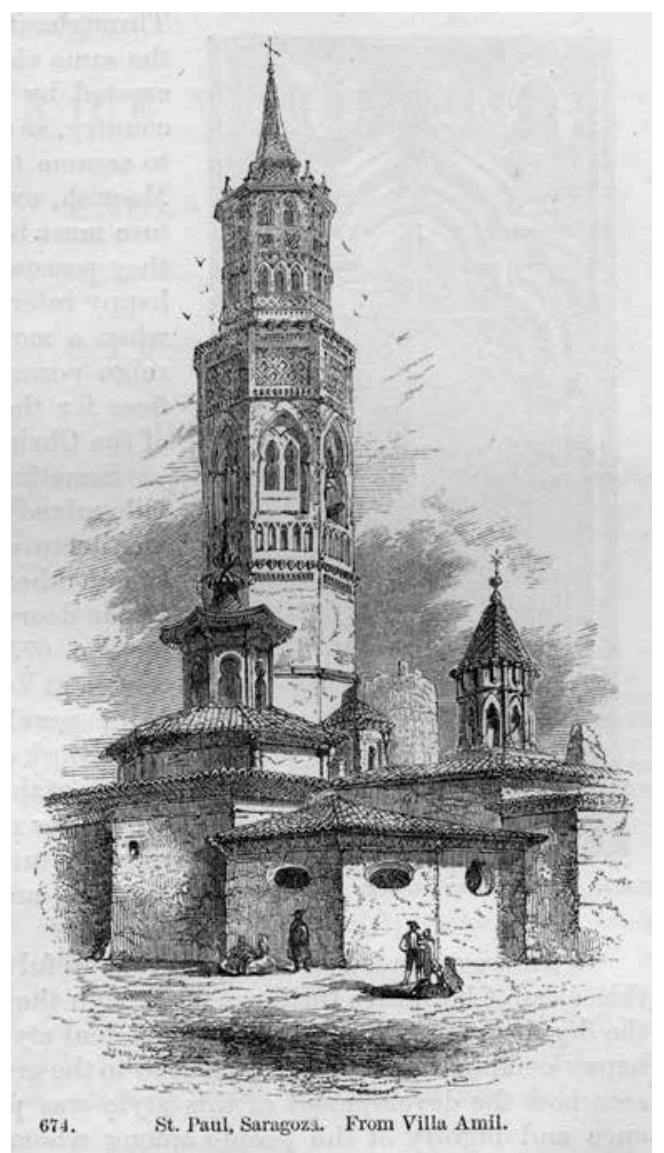

Fig. 5. Pablo, Zaragoza, copiada de una litografía original de G. Pérez Villaamil. J. Fergusson, An Illustrated Handbook of Architecture, Londres, 1855. combinaciones felices que a menudo llevan a la belleza más grande». ${ }^{35}$ Estaba particularmente impresionado por su «abundancia de ornamentación, la delicadeza del acabado, y el abandono poético que corría por cada uno de los deta\|les». ${ }^{36}$ Las torres mudéjares, retratadas con frecuencia por Villaamil, llamaron poderosamente su atención, llegando incluso a dictaminar que «poseían una belleza de una intensidad pocas veces superadas por el gótico». ${ }^{37} \mathrm{Su}$ grado de "orientalismo" le llevó a comentar que la torre de San Pablo en Zaragoza (Fig. 5), estaba «cubierta con azulejos con los brillantes colores del arte tártaro» y que su «exterior tenía de hecho un aspecto tan foráneo que se podría confundir el dibujo con uno hecho en Crimea o a los pies del Cáucaso, más que en la España católica». ${ }^{38}$ En otros casos, la apariencia orientalizante de las obras mudéjares le llevó a incluirlas en la sección de arquitectura sarracénica (islámica), como fue el caso de las sinagogas del Tránsito y Sta. Maria la Blanca, el Cristo de la Luz, o el Alcázar seviIlano. ${ }^{39}$

Esta apreciación del mudéjar es uno de los rasgos más llamativos y novedosos del manual de Fergusson porque no tenía precedentes ni en Europa y ni en la propia España. De hecho su entusiasmo fue tan apasionado que escogió una obra mudéjar, la desaparecida ermita de Humanejos (Parla, Madrid), para el frontispicio del segundo volumen de su Handbook of Architecture (Fig. 6), al tiempo que declaró que el estilo era más interesante que el románico y el gótico debido a su gran «potencial para la novedad y la belleza». ${ }^{40}$ Aplicando conceptos de la eugenesia a la arquitectura, Fergusson consideró al mudéjar como la progenie de los estilos gótico e islámico, argumentando que podría haberse convertido en un estilo "extremadamente diferente» al gótico del norte, y cuya perfección podría superar a la de sus dos progenitores. En conclusión, el mudéjar tenía todo el potencial para hacer avanzar la arquitectura en su trayectoria de progreso. Lamentablemente, argumentó Fergusson, los españoles habían desperdiciado esa oportunidad al no haber dedicado suficiente esfuerzo a su exploración y perfeccionamiento. De ello culpaba a la idiosincrasia nacional, la cual, en su opinión, carecía de genio arquitectónico y estaba dominada por un fanatismo religioso 
que había obligado a rechazar la influencia del «infiel» para adoptar el modelo cristiano del norte. Pese a su admiración por la decoración del estilo, dictaminó que «como basílicas, las iglesias mudéjares eran ciertamente inferiores a las francesas». ${ }^{41}$ Más rotunda y devastadora fue su sentencia de que «la influencia mora no había dotado a la arquitectura española de ninguna peculiaridad propia, o de nada que la hiciese preferible al gótico del norte». ${ }^{42}$ La única oportunidad de una gran contribución española al gótico, y a la arquitectura mundial, resultó no ser más que una quimera.

Tan problemáticas o más fueron las continuas comparaciones con monumentos europeos, ya que terminaron por convertirse en un discurso acerca de cómo Europa había modelado el progreso del gótico español. De hecho, la

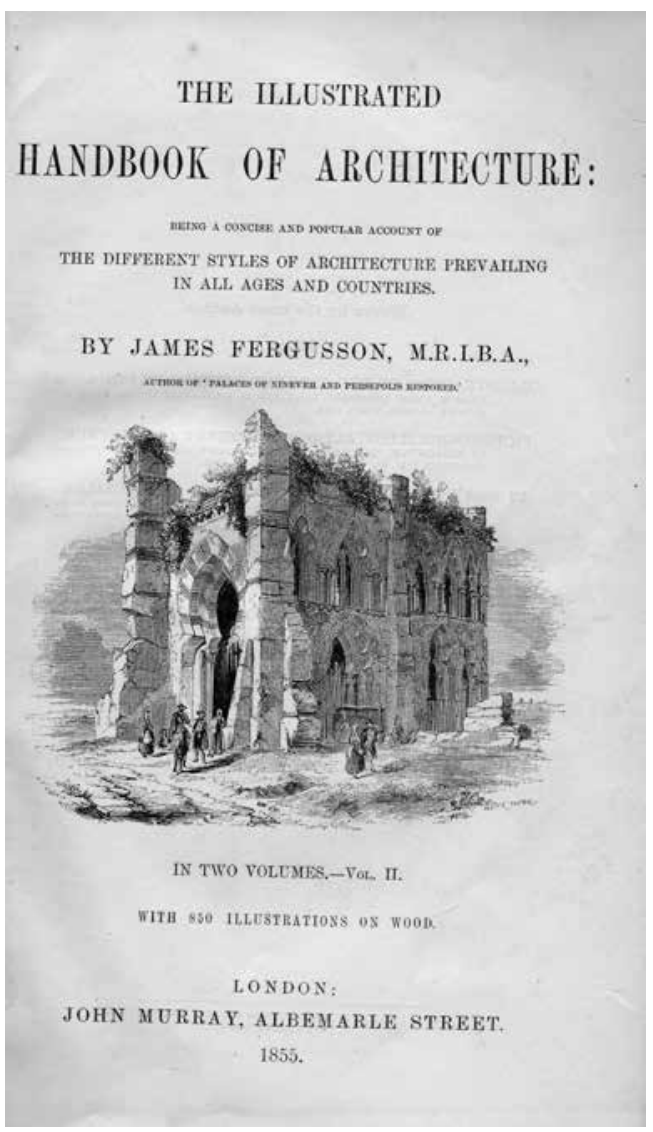

Fig. 6. Frontispicio de la primera edición del manual de F. Fergusson. conclusión final de Fergusson fue que «durante la Edad Media, usando la expresión de Luis XIV, los Pirineos no existían». ${ }^{43}$ Si bien esta declaración suponía la primera incorporación de España en el mapa del gótico europeo, es importante subrayar que lo hacía en condición de inferioridad. Para Fergusson, España no era más que una provincia artística de Francia $y$, en menor grado, de Alemania, con monumentos carentes de originalidad y que sólo aportaban deficientes versiones de excelencias ya conocidas. Interpretada como dependencia, la influencia de modelos foráneos se configuraba así como un proceso de colonización artística por parte de naciones con un genio arquitectónico muy superior al español. En gran medida, el mapa del gótico elaborado por Fergusson respondía a una historiografía de corte imperialista, en la que la supeditación del gótico español al de las grandes potencias europeas se esgrimía como un arma sutil, pero altamente efectiva, para simultáneamente remarcar y mermar el precario estanding de España en Europa y, de paso, ensalzar la gloria propia y la de las otras potencias europeas. Teniendo en cuenta el carácter pionero y amplio alcance del manual de Fergusson, su perniciosa visión del gótico español sentaba un precedente destinado a gozar de larga vida.

\section{Street: el gótico sin fronteras}

Pese la negativa visión del gótico español ofrecida por Fergusson, su denuncia del escaso conocimiento sobre el tema hizo mella en su contemporáneo George Edmund Street (18241881), quien se propondría, y lograría, subsanarla. ${ }^{44}$ Street ya era por aquel entonces un reconocido arquitecto e historiador de la arquitectura cuyo excelente juicio y amplios conocimientos estaban fuera de toda duda. A diferencia de Fergusson, Street sólo consideraba fiable el conocimiento adquirido por la inspección directa de los edificios, y, en consecuencia, había pasado tres veranos recorriendo el territorio español, anotando y dibujando cuanta fábrica medieval encontró en su camino. Sus observaciones y conclusiones fueron recogidas en su Some Account of Gothic Architecture in Spain, publicado en 1865 , la primera $y$, como ya se ha indicado, única historia de la arquitectura gótica española 
en inglés. Este estudio fue recibido por Fergusson como un «modelo en su clase», alabándola encarecidamente porque "no sólo había revolucionado el conocimiento sobre el tema» sino que también «había convertido la arquitectura española en un campo tan inteligible como el de cualquier otro país, aunque diez años antes era un misterio y un rompecabezas». ${ }^{45}$ Estos elogios tienen más mérito del que podría parecer a primera vista, ya que Fergusson y Street no siempre mantuvieron una relación cordial. Sus personalidades eran opuestas, y, como es de imaginar, Fergusson no aprobaba la práctica arquitectónica de Street, encuadrada exclusivamente en el Gothic Revival. ${ }^{46}$ Sus diferencias, sin embargo, fueron dejadas convenientemente de lado al proporcionarle Street lo que él más nesitaba: plantas, alzados, descripciones detalladas y fidedignas, medidas precisas de numerosos edificios, muchos de ellos hasta entonces desconocidos, y todo ello articulado en un discurso coherente y detallado del desarrollo del gótico en España.

Al igual que Fergusson, Street también estaba altamente interesado en ubicar el gótico español dentro del contexto europeo, pero su motivación era otra. Más que establecer un ranking de góticos europeos, Street, quien era un hombre profundamente religioso, estaba interesado en demostrar que el gótico era un estilo en el que el sentimiento cristiano universal predominaba sobre cualquier idiosincrasia nacional. Para él, el verdadero motor del gótico era su espíritu cristiano y éste no entendía de fronteras. Su interés en el gótico español, por tanto, no radicaba en cuál era la contribución española al progreso de la arquitectura, sino en demostrar cómo el espíritu cristiano del estilo habría triunfado incluso en un terreno tan adverso como España, donde la presencia musulmana había sido tan intensa y prolongada. El propósito final de Street era refutar la creencia bien difundida de que el gótico español estaba fuertemente influenciado por las tradiciones islámicas, y para ello consideró fundamental proporcionar pruebas fidedignas de su semejanza con otros edificios góticos europeos cuya pureza y cristiandad estaban fuera de toda duda

Pese a lo dispar de sus respectivas agendas, Street, al igual que Fergusson, terminó por con- vertir los lazos estilísticos con otras zonas europeas en el pilar fundamental de su estudio del gótico español. Su actitud hacia las influencias extranjeras, sin embargo, era muy diferente. Street, a diferencia de la gran mayoría de sus compatriotas, no compartía la concepción nacionalista del gótico, sino que lo consideraba un estilo transnacional. La idea de góticos nacionales, argumentaba Street, era una incongruencia, ya que los artistas medievales fueron en su mayoría itinerantes mientras que las fronteras políticas habían sido inestables y, en cualquier caso, nada tenían que ver con las decimonónicas. Según él, la imitación de modelos foráneos había sido una práctica común en la Edad Media, y era digna de emulación, tal y como hizo él mismo en sus numerosos viajes por Europa. Así pues, lejos de considerar las influencias extranjeras como síntoma de la carencia de genio artístico, Street las concibió como pruebas de que los edificios góticos españoles no eran, como se solía pensar, una excepción a la regla general, sino todo lo contrario. ${ }^{47}$ Con este mismo objetivo, Street también minimizó considerablemente la influencia islámica y practicamente ignoró al mudéjar y la arquitectura andaluza. Todo ello le permitió declarar que «estaba más que satisfecho con la pureza y belleza de la arquitectura cristiana de España». ${ }^{48} \mathrm{El}$ estudio de Street, pues, presentaba un mapa alternativo del gotico, carente de fronteras internas nacionales, y cuyos confines venían determinados por la expansión de la cristiandad en la Edad Media. Su geografía del gótico integraba la Península Ibérica como parte esencial del estilo, no como una colonia artística, y de paso reclamaba la España medieval para la Cristiandad.

\section{Los Pirineos: una frontera etnográfica}

La información proporcionada por Street fue utilizada por Fergusson en la segunda edición de su manual, rebautizado como A History of Architecture, y publicado en dos volumenes, el primero en 1865, y el segundo, incluyendo el gótico español, en 1867. Pero Fergusson, quien no en vano había sido calificado como «uno de los hombres más difíciles de convencer y conquistar» no se limitó a copiar a Street sino que aprovechó su información para construir su propia interpretación. ${ }^{49}$ En esta edición, Fergusson 
re-elaboró totalmente su discurso sobre el gótico español, duplicando su extensión y número de ilustraciones, muchas de las cuales procedían del estudio de Street. ${ }^{50}$ También transformó su metodología historiográfica con el fin de integrar la historia de la arquitectura en una ciencia de reciente invención: la etnografía. El resultado fue, pese a la visión positiva de Street, un reforzamiento de sus opiniones negativas previas, recogidas en un capítulo nuevo que intercaló a modo de introducción a la arquitectura medieval española, y en el que sus ataques fueron más explícitos, elaborados y virulentos. La amplia frontera del gótico establecida por Street fue también rechazada, y los Pirineos volvieron a ser una vez más el confín del estilo.

El mayor impacto de Street en Fergusson se detecta en numerosas correcciones relativas a las filiaciones estilísticas y más especialmente en la nueva apreciación de un grupo de edificios que había omitido en la edición previa: el gótico catalán. De la mano de Street, Fergusson descubrió la elegancia, belleza e ingenuidad arquitectónica demostrada en las iglesias góticas catalanas del siglo XIV, apostillando que no tenían paralelo en Francia. "Los españoles», escribió, «una vez que comprendieron la idea de estos halls abovedados espaciosos y descubrieron la forma de construirlos, desarrollaron este principio más allá que ningun otro país al norte de los Pirineos». ${ }^{51}$ En este sentido, dictaminó que la catedral de Girona (Fig. 7) «debía de ser considerada como unos de los mejores diseños de la Edad Media, y uno de los más originales de España». ${ }^{52}$ También admiró que el diseño de las iglesias catalanas se adaptase mas a las necesidades de la congregación que a las de las liturgias del clero, concluyendo que Sta María del Mar, en Barcelona, era «en cuanto a iglesia congregacional, superior a la mayoría de los diseños de la Edad Media». ${ }^{53} \mathrm{El}$ desdén de Street por el mudéjar no fue tampoco del todo ignorado, y parece haber influenciado la decisión de suprimir la ermita de Humanejos del frontispicio del segundo volumen, así como en la eliminación de la mayor parte de comentarios acerca de influencias orientales en los edificios románicos y góticos.

Al igual que en la primera edición, Fergusson también invalidó sus elogios con objeciones continuas, concluyendo que los edificios «nunca eran completamente satisfactorios». ${ }^{54}$ Por ejemplo, la catedral de Girona que tanto había admirado, fue criticada porque el diseño de la transición de la cabecera a la nave ofrecía una ocasión magnífica para la decoración que no fué aprovechada, apostillando que era mucho esperar de España que se hubiese hecho lo contrario, como hubiese sucedido si el arquitecto hubiese sido un artista verdadero, entendiendo por ello un arquitecto del norte de Europa..$^{55}$ En un giro irónico, las bien intencionadas filiaciones estilísticas razonadas por Street fueron manipuladas por Fergusson para denigrar el gótico español. ${ }^{56}$ Gracias a ellas pudo argumentar que éste «no era indígena, sino prestado de otras naciones, y consecuentemente practicado de una forma mucho más caprichosa que si hubiese sido elaborado por los mismos españoles». ${ }^{57}$ En su opinión, los estilos peculiares de España nunca pasaron de su fase embrionaria, ya que siempre fueron suplantados por un nuevo estilo extranjero. La historia de la arquitectura española con-

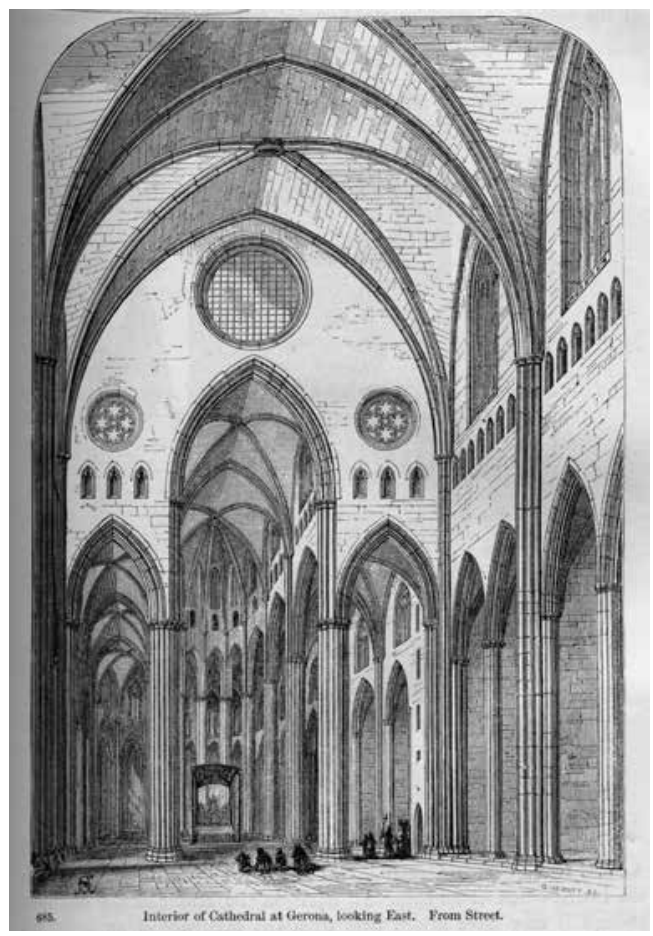

Fig. 7. Catedral de Gerona, tomada de Street. J. Fergusson, $A$ History of Architecture, Londres, 1867. 
sistía en una importación tras otra: de Francia, Alemania, Italia y los moros. ${ }^{58}$ Los españoles, concluía en otro lugar, "habrían también adoptado los estilos chinos y mejicanos con la misma presteza, si esos estilos les hubiesen proporcionado lugares de culto tan preciosos y apropiados a sus fines como los que tienen ahora». ${ }^{59}$ En suma, «España podría seguir a Francia [en la organización del libro], ya que la mayoría de sus peculiaridades arquitectónicas fueron tomadas prestadas de ese país (...) mientras que en su conjunto, las lecciones que se pudiesen aprender de su arte eran tan pocas, que era relativamente irrelevante en qué secuencia se colocase a este país». ${ }^{60}$ Para Fergusson, el gótico español pertenecía en el grupo de «monkey styles» y en realidad no podía ni siquiera ser considerado como gótico propiamente dicho, y por tanto la contribución de España en la evolución del estilo era inexistente.

En esta segunda edición, Fergusson trató de dar más validez a su menosprecio del gótico español aduciendo argumentos de corte más científico proporcionados por la etnografía. Al igual que muchos de sus contemporáneos, Fergusson defendía que la raza determinaba las creencias religiosas, códigos éticos, sistemas de gobierno, patrones económicos, así como aptitudes artísticas e inclinaciones de todo tipo, y era, consecuentemente, la clave de la historia de la humanidad. ${ }^{61}$ Su objetivo en esta edición era precisamente demostrar que la historia de la arquitectura podría proporcionar información sobre los orígenes y evolución de las diferentes razas, especialmente en el caso de culturas remotas dada la ausencia de otro tipo de evidencia. Sus novedosos y peculiares argumentos al respecto fueron recogidos en un nuevo capítulo de su manual titulado «Etnografía aplicada al arte arquitectónico». El sistema de Fergusson se fundamentaba en su creencia de que los estilos eran creados por la sociedad, no por arquitectos individuales, por lo que la arquitectura debería ser considerada como "una de las mejores formas de estudiar la historia del hombre, o de entender su naturaleza o aspiraciones». ${ }^{62}$ En sus propias palabras

Cuando un estilo expresa los conocimientos intimos de los procesos de la naturaleza por parte de sus creadores, también expresa sus sentimientos, y con sus sentimientos, su nacionalidad. Es así que, al mirar a los edificios antiguos, no sólo podemos decir en qué estado de civilización vivían sus constructores, o cuán avanzados estaban en las artes, sino que también podemos decir, casi con total certeza, a qué raza pertenecían, y qué afinidades tenían con otras razas o tribus de la humanidad. No conozco ni una sola excepción a esta regla; y en mi juicio, creo que la arquitectura es, en todos los casos, una evidencia de la raza tan correcta como el lenguaje, y de mucha más fácil aplicación y entendimiento. Los lenguajes se alteran y mezclan unos con otros, y una vez que se ha producido un cambio es extremadamente difícil rastrearlo hasta sus orígenes, y dilucidar los elementos que lo componían; pero un edificio, una vez que ha sido construido, permanece inalterable para testificar acerca del tiempo en que se construyó, y los sentimientos y motivos de sus constructores permanecen estampados indeleblemente mientras dure el edificio. ${ }^{63}$

Dado que la historia de la arquitectura era «la más íntimamente ligada a los intereses y sentimientos del hombre, y la que mejor y más claramente expresaba y recogía lo que el hombre hacía y sentía en épocas pasadas», eso la convertía en la ciencia más útil para indagar en la historia de la humanidad. ${ }^{64}$ Este hecho, argumentaba Fergusson con gran vehemencia, era lo que elevaba la disciplina de mera arqueología a la altura de una ciencia filosófica.

La creencia de que la arquitectura podía expresar el carácter de un pueblo tenía ya una larga tradición en Europa desde la llustración, y se había intensificado en el siglo XIX al ser considerada como un instrumento primordial para conocer la historia y carácter de una nación. El enfoque etnográfico, sin embargo, fue una innovación original de Fergusson y produjo una de las combinaciones interdisciplinarias más curiosas dentro de la historiografía del gótico hispano. En teoría, su propósito era deducir la raza e historia de un país a partir de sus edificios; sin embargo en el caso español el proceso parece invertirse. La impresión que produce la lectura de su manual es que fue una imagen pre-establecida de los españoles la que dictó la interpretación del gótico peninsular, y que fue a posteriori cuando se le buscó una justificación "científica» de corte racial. España ya llevaba varios siglos siendo 
víctima de una reputación infame en Europa. El fenómeno, conocido como la Leyenda Negra, caracterizaba a los españoles como seres irracionales, intolerantes, fanáticos religiosos, violentos, y atrasados en todos los campos del saber. ${ }^{65}$ La influencia de la Leyenda Negra en Fergusson está fuera de toda duda y se evidenciaba en numerosos comentarios prejuiciosos, como cuando afirmó ya en su primera edición de la historia de la arquitectura de 1855, que «los españoles carecían tanto de cualidades artísticas como de muchas otras importantes virtudes», o que no eran un pueblo ni arquitectónico ni inventivo. ${ }^{66}$ En su segunda edición, acometió la labor de proporcionar una explicación larga y detallada del cómo y porqué los españoles eran incapaces de producir una arquitectura original de calidad. Sus argumentos ampliaban substancialmente el estereotipo de la Leyenda Negra e invertían la relación causal, al esgrimir, por primera vez, el gótico como prueba definitiva de la inferioridad española. ${ }^{67}$

El caso español era mas grave que el de otros países carentes de inventiva, argumentaba Fergusson, porque los españoles profesaban una pasión por la arquitectura más intensa que la de cualquier otro país europeo. ${ }^{68}$ Esta incapacidad para crear algo tan apreciado, era, en sus ojos, una prueba fehaciente de su patética incompetencia en materia arquitectónica. Es más, en el único caso en el que esta "raza inartística» fue capaz de crear un diseño original y propio -la ubicación del coro en la nave mayor-el resultado no podía haber sido, en su opinión, más nefasto. "Si los españoles fuesen un pueblo artístico», razonaba, "habrían inventado un 'envoltorio' adecuado para contener este tipo de coro; pero colocarlo en medio de una iglesia francesa era un error sin redención posible». ${ }^{69}$ Pero la prueba quizás más ilustrativa era el mudéjar, ya que Fergusson atribuyó su fracaso al hecho de que «los españoles eran incapaces de elaborar ninguna forma artística». ${ }^{70}$ Ese problema, argumentaba, no se limitaba a la Edad Media, sino que era una constante en España. «En general», dictaminaba en otro lugar, "quizás no estaríamos errados al asumir que los españoles se encuentran entre los pueblos menos artísticos de Europa». El problema se acentuaba, según Fergusson, porque los españoles reunían todos los elementos necesa- rios para haber creado una buena arquitectura, tales como buen clima, modelos, materiales, conocimientos, etc., y «a pesar de ello no habían conseguido llegar a la altura de Italia o Francia, y parecían totalmente incapaces de apreciar las excelencias del arte arquitectónico». ${ }^{71}$

Fergusson estaba convencido de que esta incapacidad proporcionaba suficiente evidencia para dilucidar una de los grandes interrogantes de la etnografía: ¿cuál era la verdadera o dominante raza de los españoles, dada la mezcolanza de pueblos que habían habitado la península? En su opinión había cuatro razas principales: la turania, la semítica, la celta y la aria. Entre ellas, la celta era considerada por él como la más artísticamente inclinada, llegando a defender que no era posible la creación artística sin ella, así como que la calidad de una arquitectura nacional era directamente proporcional al porcentaje de sangre celta de sus habitantes. ${ }^{72}$ Dado que los españoles eran incapaces de crear una arquitectura propia, Fergusson concluyó que «el elemento celta estaba ausente de esa olla podrida de naciones» que era España. ${ }^{73}$ También rechazó que fuesen turanios, pues éstos habían siempre destacado en arquitectura y solían dejar tras de sí magnificas tumbas que no existían en España. Así pues, quedaban sólo dos ingredientes posibles en la "olla podrida» española, los arios y los semitas, los cuales identificó con los visigodos y los moros respectivamente. En su sistema, no podría ser de otra forma ya que estos dos pueblos eran los menos dotados para la arquitectura, y por lo tanto armonizaban perfectamente con la «realidad» arquitectónica española. ${ }^{74} \mathrm{Con}$ su sarcamo habitual se preguntaba si «los Iberos habían sido un pueblo semita, o si pertenecían a una raza todavía más ruda o menos artística», un insulto cuya dimensión se aprecia mejor al tener en cuenta que los semitas, en palabras de Fergusson, eran incapaces de levantar un edificio que mereciese el nombre de tal. ${ }^{75}$ No debemos de olvidar que este tipo de comentarios, lejos de ser considerados racistas o anti-semitas en su época, eran entendidos como pruebas y explicaciones "científicas» de la supuesta carencia del genio artístico de los españoles. ${ }^{76}$

Los criterios raciales y racistas fueron también aplicados al mudéjar con el fin de diluci- 
dar si efectivamente este estilo tenía el potencial de convertirse en uno de los más grandes de la historia de la arquitectura. En esta segunda edición, Fergusson no parece tan seguro como en la previa de que el mudéjar tuviese en sí la semilla de la grandeza. "Si conociésemos mejor las relaciones étnicas de los moros que conquistaron España en el siglo VIII», se preguntaba, «quizás podríamos predecir si habría sido posible producir un híbrido fértil a partir de padres tan diferentes». Pero los moros españoles parecían no ser del tipo racial adecuado. A pesar de ser considerados como «uno de los pueblos más perfectos en lo que se refiere a la ornamentación, no eran arquitectos». "Tampoco pertenecían a ninguna de las razas de grandes constructores», explicaba, «porque durante todo el tiempo que estuvieron en España no exhibieron ninguna habilidad constructiva, ni destreza en la organización de sus plantas, ni afan de magnificencia arquitectónica». "Si los habitantes de Toledo hubiesen sido franceses o de cualquier otra raza celta», especulaba Fergusson, "la combinación de su habilidad constructiva con el buen gusto en el detalle de los moros habría producido uno de los mejores resultados». ${ }^{77}$ En esta segunda edición de su manual, Fergusson incluyó también una interesante comparación entre el mudéjar y el gótico. El paralelo entre ambos estilo fue argumentado principalmente con criterios arquitectónicos, incluyendo el razonamiento habitual de que el gótico era superior en cuanto a concepción arquitectónica mientras que el mudéjar era más elegante en los detalles ornamentales. En esta ocasión, sin embargo, Fergusson añadió que la diferencia principal radicaba en sus diseños estructurales, pues el gótico utilizaba bóvedas de piedra, mientras que «los Sarracenos de España», «nunca intentaron construir con bóvedas o cúpulas, sino que siempre se contentaron con cubiertas de madera». Lo más llamativo, quizás, es la conclusión que Fergusson derivó de esta diferencia por las connotaciones racistas, e incluso sexistas que transpiraba. Para él, la utilización de bóvedas suponía un reto intelectual de mucha mayor envergadura que las cubiertas de madera, y ese componente intelectual obligó a los arquitectos góticos «a trabajar como hombres [mi cursiva]». ${ }^{78}$ Las implicaciones de este comentario son profundas. Por un lado, establecía una jerar- quía entre la capacidad intelectual superior de los arquitectos góticos y la inferior de los «sarracenos», o lo que es lo mismo, la superioridad de Europa/Occidente sobre el «Oriente». Y por el otro lado, sugería que la inteligencia era una cualidad exclusivamente masculina, lo cual además de implicar la inferioridad de las mujeres, ponía en duda la virilidad de los «orientales», y subrayaba su inferioridad a través de su percepción como afeminados

Como hemos visto, en esta edición, el gótico se convirtió en un producto del genio celta, de Occidente y de Europa, por lo que un pueblo semita como el español nunca podría haberlo entendido, ni copiarlo adecuadamente, ni mucho menos aportar ninguna contribución; de hecho el gótico español no se podía ni considerar gótico. Los Pirineos, los cuales, recordemos, habían sido eliminados previamente por Fergusson como frontera estilística al convertir España era una provincia artística de Francia, se erigían ahora como formidable frontera etnográfica que separaba una Francia predominantemente celta de una España dominada por el componente semita. Esta diferenciación racial tenía importantes implicaciones para la determinación del estanding de España en Europa. Al añadir un componente racial, Fergusson estaba yendo más allá de la especificidad artística para convertir el gótico en el estándar del grado de relativa civilización y superioridad cultural de las diversas naciones. La identificación, predominante en la época del gótico con la Europa atlántica, y por implicación con la cultura occidental, relegaba una España supuestamente semita a la categoría de territorio o frontera infradesarrollada, al margen de la superior civilización occidental representada por Francia, Alemania y, por supuesto, Gran Bretaña. El mapa del gótico se convertía así en un mapa etnográfico, cuya frontera pirenaica determinaba no sólo el límite meridional de la geografía del gótico, sino también de la identidad europea.

\section{La frontera del Gótico}

La popularidad y carácter pionero del manual de Fergusson lo convirtieron en fuente de consulta obligada para posteriores estudiosos e investigadores, y como tal, su influencia no puede ser supervalorada. Su impacto se detecta, por 
ejemplo en una de las más respetadas obras de referencia sobre el tema en inglés, la popular Encyclopedia of Architecture, de Gwilt, publicada en Londres en 1891, en la que el gótico español fue relegado a la sección titulada «Imitative Gothic». ${ }^{79}$ Al otro lado del Atlántico, el profesor de Harvard University, C.H.Moore también se hizo eco de los argumentos de Fergusson en su influyente Development and Character of Gothic Architecture, publicado simultáneamente en Londres y Nueva York el año anterior, en 1890, y con una segunda edición en 1899. Este estudio anunciaba en su tabla de contenidos que «las condiciones sociales y políticas de España no [eran] favorables al desarrollo de las artes», mientras que en el texto argumentaba que «la arquitectura apuntada de España no era gótica en términos absolutamente estrictos». ${ }^{80}$ En opinión de Moore, incluso la escultura gótica española era también, como las iglesias, "copiada sin ningún genio de la escultura de Francia». Con una actitud tan prejuiciosa como la de Fergusson, Moore declaró que «de todas las naciones occidentales, España, durante la Edad Media, era la más atrasada en cuanto a las condiciones políticas y organizaciones sociales, así como en cuanto a la vida intelectual y moral, que favorecían el desarrollo de las bellas artes». ${ }^{81}$ Estas dañinas opiniones debieron de haber tenido un alcance cualitativo y cuantitativo considerable, especialmente si tenemos en cuenta el prestigio de la institutición en la que trabajaba, y que su dispersión se multiplicó exponencialmente a través de sus alumnos, muchos de los cuales se convertirían, a su vez, en profesores universitarios y conservadores de museos. No es de extrañar pues que quince años después $A$ History of Architecture del norteamericano R. Sturgis, siguiese argumentando que el gótico español «debería ser estudiado inmediatamente después de Francia; ya que la influencia francesa fue más directa y contínua, y procedía de una mayor variedad de fuentes regionales y monásticas que en cualquier otro país». ${ }^{82}$ Más de dos décadas después, la más específica History of Spanish Architecture de Bernard Bevan, publicada en Londres en 1938, única historia de la arquitectura española escrita en inglés hasta hoy en día, volvía a insistir en la idea de una España que se ubicaba en la periferia de la Europa civilizada y cuyas ideas de civilización eran prácticamente importadas en su totalidad. ${ }^{83}$ El último estudio monográfico en inglés hasta la fecha dedicado a la arquitectura española, The Cathedrals of Spain, de J.H. Harvey, publicado en Londres en 1957, todavía recogía la creencia de que el progreso de la arquitectura española obedecía a la importación de arquitectos extranjeros. ${ }^{84}$

Los comentarios ofensivos acerca de España terminarían por desaparecer de los manuales, pero no así la visión de su gótico fomentada por Fergusson. Como se ha visto al comienzo de este artículo, el gótico español ha sido omitido en la mayoría de los casos. Con respecto a los escasos manuales en los que aperece, suele ser incluido como prueba de la expansión del gótico francés a otros países, y limitando los ejemplos a las catedrales de Burgos, León y Toledo. Las historias de la arquitectura gótica han sido más proclives a incluir el gótico español, pero en esos casos, la selección de monumentos incluidos -énfasis en el gótico catalán y el tardogótico castellanosigue bastante fielmente la del manual de Fergusson con la adicción de la catedral de Palma de Mallorca, cuya inclusión se debe al estudio de Cram. En comparación con Fergusson, el impacto de Street parece haber sido bastante reducido y mediatizado en su mayor parte por el mismo Fergusson. Todo parece indicar que en lo referente a la arquitectura gótica, éste último fue el más influyente de los dos, e incluso no sería aventurado atribuir la ausencia de seguidores de Street a Fergusson.

El sustento principal de esta tradición historiográfica fue la creencia de que los monumentos españoles no tenían nada nuevo que ofrecer y que sus monumentos eran copias inferiores de las catedrales francesas o alemanas. Desde esta perspectiva, el énfasis en las influencias extranjeras por parte de Fergusson y Street fueron especialmente nefastas. Tal y como lo resumió Bevan, la historia de la arquitectura española consistía «principalmente en el rastreo de influencias foráneas y el estudio de cómo se naturalizaron». ${ }^{85}$ Aunque algunos estudios, especialmente los más recientes, han sido bien intencionados en su obsesión por las influencias, el resultado final es siempre el mismo: el interés intrínseco de los monumentos españoles es reducido dada su 
escasa originalidad. Como argumentaba Bevan siguiendo a Fergusson, «España no añadió nada a las bellezas de gótico francés, sino que más bien las simplificó y disminuyó como si fuese incapaz de apreciar las posibilidades del estilo». ${ }^{86}$ El interés de los edificos españoles exclusivamente extrínseco, limitado a su relación con el canon gótico consagrado por la historiografía tradicional, especialmente las catedrales francesas, cuya superioridad se veía así resaltada por su impacto en España y la incapacidad de los españoles para superarlo.

Como señalé al comienzo de este artículo, el mapa del gótico ofrecido por los manuales de historia del arte en inglés tiende a marginar España. La frontera del gótico por ellos perpetuada obedece en gran parte, como espero haber demostrado, a prejuicios contra los españoles fomentados por la Leyenda Negra, a un imperialismo cultural que favorecía a las grandes potencias europeas -Francia, Gran Bretaña y Alemania-, y a una historiografía orientalista y antisemita que desdeñaba la raza semítica como artísticamente inferior. ${ }^{87}$ El gótico español, de la mano de Fergusson y sus seguidores, se convirtió así en una prueba más de la raza «oriental» y «semita» de los españoles, y, en última instancia, de la imposibilidad de que España perteneciese a Europa. No es casualidad que las naciones con el «mejor gótico» son precisamente las superpotencias modernas de Europa. Desde el siglo XIX, tanto Francia como Gran Bretaña y Alemania han utilizado este estilo para definir y exaltar su imagen nacional -Notre-Dame de París, las Casas del Parlamento en Londres, la catedral de Colonia- así como para alardear de su superioridad cultural occidental, y justificar por este motivo sus ambiciones imperialistas. La marginación actual del gótico español, al igual que el de otros paises europeos, es una consecuencia directa de este fenómeno decimonónico. Resulta tambien curioso comprobar como la mayor presencia del gótico español en estudios recientes, tales como Medieval Architecture de Nicola Coldstream, han coincidido con la incorporación de España en la Unión Europea y un esfuerzo consciente globalizador y antiorientalista por parte de los historiadores. ${ }^{88}$ En conclusión, la frontera del gótico no es una frontera artística, sino que parece haber estado más determinada por la política, los prejuicios raciales y los estereotipos nacionales que por la arquitectura misma.

\section{NOTAS}

1 Janson's History of Art: The Western Tradition, AAVV, Upper Saddle River, NJ, $20118^{\mathrm{a}}$ ed. Otros ejemplos ilustrativos son los incluidos en Marilyn Stokstad, Art History, Upper Saddle River, NJ, 2005, $2^{\text {a }}$ ed, y por la misma autora Art: A Brief History, Upper Saddler River, NJ, 2007, $3^{\text {a }}$ ed. La Kunstgeographie ha estado recibiendo una atención considerable en años recientes, tanto desde el punto de vista teórico como de estudios puntuales de ejemplos específicos. Véase al respecto Katarzyna Murawska-Muthesius (ed.), Borders in Art: Revisiting Kunstgeographie. The Proceedings of the Forth Joint Conference of Polish and English Art Historians, Varsovia, 2000; Thomas DaCosta Kaufmann, Toward a Geography of Art, Chicago-Londres, 2004; Thomas DaCosta Kaufmann y Elizabeth Pilliod, eds., Time and Place: The Geohistory of Art, Burlington, VT, 2005. Para estudios más específicos de la geografía del gótico véase Povilas Reklaitis, "The Problem of the Eastern Borders of Gothic Architecture", Lithuanian Quarterly Journal of Arts and Sciences, vol. 10, n², 1964, http://www.lituanus.org/1964/64_2_03_Reklaitis.html. Sobre los Pirineos como frontera que definió las identidades nacionales independientes de España y Francia desde una perspectiva histórica, véase Peter Shahlins, Boundaries: The Making of France and Spain in the Pyrenees, Berkerley, University of California Press, 1989.

2 Esta afirmación está fundamentada en el examen de un numero significativo, pero no exhaustivo, de las historias generales del arte, historias de la arquitectura, e historias del arte medieval en inglés. Algunos ejemplos de negligencia total del gótico español son los manuales más tradicionales y populares tales como L.S. Adams, A History of Western Art, Madison, Wis., 1994 ( $5^{a}$ ed. 2011); William Fleming, Arts and Ideas, Nueva York, 1955 (10 ${ }^{\text {th }}$ ed., 2004, revisada por Mary Warner); Gardner's Art through the Ages, 14 ${ }^{\text {th }}$ ed. Wadsworth, 2013, curiosamente, esta historia del arte que fue publicada por primera vez en 1926, sí solía incluir, aunque muy brevemente, el gótico español en sus primeras ediciones; $\mathrm{H}$. Honour, I. Fleming, The Visual Arts: a History, Englewood Cliffs, NY, 1982 (7 ${ }^{\text {a }}$ ed. 2013); H.W. Janson; A History of Art, New York 1962, (7 $7^{\text {a }}$ ed, New Jersey, 2011). Otras historias del arte más recientes que también omiten la arquitectura gótica española son J.Thuillier, History of Art, Paris-London, 2003 (traducida del francés); D. Wilkins, Art past, art present, New York, 1990 (úl- 
tima ed. 1997); The Boundless Art History, historia en versión digital https:// www.boundless.com/art-history/; la obra colectiva de Phaidon Press, Art in Time: A World History of Styles and Movements, Londres, 1214. En lo que se refiere a historias generales de la arquitectura, el gótico español también está ausente de Spiro Kostof, A History of Architecture: settings and rituals, New York, 1995 (última reimpresión en 2010); M.Moffett, World History of Architecture, Boston, 2003 ( $3^{\mathrm{a}}$ ed. 2013); M.Raeburn, Architecture of the Western World, New York, 1980 (última ed. en 1988); F. Ching, A Global History of Architecture, Hoboken, NJ, 2006 (última ed. 2011); L. Wodehouse and M. Moffett, A History of Western Architecture, Mountain View, CA, 1989; Richard Ingersoll, Spiro Kostof, World Architecture: a Cross-Cultural History, Oxford University Press 2013. Entre las historias del arte medieval que no incluyen arquitectura gótica española están Robert Calkins, Monuments of Medieval Art, Ithaca, NY, 1979 (última reimpresión 1989); J. Snyder, Medieval Art. Painting.Sculpture. Architecture. 4th-14th century, New York, 1988 (última reimpresión 2006); Marilyn Stokstad, Medieval Art, Upper Saddle River, NJ, 2011 (reimpresión de la $2^{\text {a }}$ ed. 2004), su primera edición de 1985 sí incluía el gótico español, y es curioso que se haya eliminado en ediciones posteriores; George Zarnecki, Art of the Medieval World: Architecture, Sculpture, Painting, Harry Abrams, New York, 1975. Incluso hay historias del arte gótico que tampoco incluyen la arquitectura gótica de España como por ejemplo Otto von Simson, The Gothic Cathedral: Origins of Gothic Architecture and the Medieval Concept of Order, Princeton University Press, 1956.

${ }^{3}$ Aunque este artículo se centra en la fortuna de la arquitectura gótica, se ha incluído también el mudéjar porque en las discusiones decimonónicas este último estilo era considerado una variante del gótico español. Resulta increíble que la única historia de la arquitectura gótica española en inglés sea todavía la de G. E. Street, Some Account of Gothic Architecture in Spain, Londres, 1865. Este estudio, un auténtico clásico sobre el tema, ha sido objeto de una segunda edición en 1869, y una tercera edición revisada por G.G. King publicada en 1914, con reimpresiones en 1969 y 1980; fue también traducida al español en 1926 por Román Loredo. R.A. Cram, The Cathedral of Palma de Mallorca; an Architectural Study, Cambridge, Mass., 1932. También hubo otro estudio sobre esta catedral por John O. Brostrup, John O, y Thomas T. Waterman. The Cathedral of Palma De Mallorca: An Exhibition of Studies. Washington, D.C., 1938, el cual tuvo escasísima divulgación, presente en sólo una biblioteca según Worldcat, y por eso no lo tengo en cuenta. Más recientemente, James W. Millard ha publicado Catalan Gothic Architecture: A Concise Guide to Gothic cathedrals, monasteries and public buildings in Catalonia, Thornton-Vleverly, 2007; desafortunadamente no he sido capaz de consultar este libro, pero parece más una publicación divulgativa que un texto académico. Además de estos libros hay artículos monográficos sobre problemas puntuales de algunos edificios góticos españoles, que he omitido dado que no alteran el hecho de la marginalización de la arquitectura gótica española dentro del marco de referencia aquí propuesto. Hubo también estudios por parte de otros historiadores europeos: August Mayer, Gotik in Spanien, Leipzig, 1928, Élie Lambert, L'Art gothique en Espagne aux XII et XIII siècles, Paris, 1931, y Pierre Lavedan, L'Architecture gothique religieuse en Catalogne, Valence et Baléares, Paris, 1935

${ }^{4}$ Como excepción significativa hay que mencionar la biblioteca de la Escuela Superior Técnica de Arquitectura de Madrid, que sí cuenta con varias de sus obras. La presencia de Fergusson en las colecciones de la Escuela de Arquitectura de Barcelona y la Biblioteca Nacional de España, sin embargo, es muy reducida y no incluye sus obras principales.

${ }^{5}$ Nikolaus Pevsner, "James Fergusson", Some Architectural Writers of the Nineteenth Century, Oxford, 1972, 238-251, esp. 238.

6 "Obituary. James Fergusson", The Builder, 16 de Enero de 1886, 113. Todas la traducciones del inglés son mías y en ocasiones he realizado pequeños cambios que sacrifican la literalidad del original, pero nunca el contenido, con el fin de facilitar su mejor integración en mi propio discurso.

7 Sobre la biografía y obra de James Fergusson véanse L.Stephen y S.Lee, "Fergusson, James (18081886)", Dictionary of National Biography, Oxford y Nueva York, 2004, vol. 19; W. H. White, "James Fergusson: a Sketch of his Life", en J.Fergusson, History of the Modern Styles of Architecture, Robert Kerr (ed.), Nueva York, 1891, XXVII-XXXVIII; y sus necrológicas en Times (Londres), 11 de Enero de 1886; Athenaeum (Londres), 16 de Enero de 1886; y The Builder (Londres), 50 (16 de Enero de 1886), 113-115. Sobre la metodología historiográfica e ideas de James Fergusson véanse R. Elwall, "James Fergusson (1808-1886): a Pioneering Architectural Historian", RSA Journal 139 (Mayo, 1991), 393404; N. Pevsner, op.cit.; D.Watkin, The Rise of Architectural History, Londres, 1980, 82-86; y M. Craig, "James Fergusson", Concerning Architecture. Essays on Architectural Writers and Writing Presented to Nikolaus Pevsner, ed. por John Summerson, Londres, 1968, 140-152; Sobre la contribución de Fergusson al conocimiento de la arquitectura india véanse T.G.Thakurta "Fergusson, James", The Dictionary of Art, Nueva York, 1994; Pramod Chandra, On the Study of Indian Art, Cambridge Mass, 1983, 11-20; Partha Mitter, Much Maligned Monsters: History of European Reactions to Indian Art, Oxford, 1977, 260-267.

${ }^{8}$ Athenaeum, 110 y 109.

9 La History of Architecture de Fergusson tuvo muchas ediciones y transformaciones. Su primera edición apareció bajo el título de The Illustrated Handbook of Architecture: Being a Concise and Popular Account of the Different Styles of Architecture Prevailing in All Ages and Countries, Londres, 1855, con una segunda edición en 1859. Poco después, Fergusson publicó como obra complementaria A History of Modern Styles of Architecture, Being a Sequel to the "Handbook of Architecture", Londres, 1862. Estas dos obras fueron poco después revisadas y fundidas en una solo obra, A History 
of Architecture in All Countries, from the Earliest Times to the Present Day, 3 vols., Londres, 1865-67. Esta obra, a su vez, sufrió una revisión y aumento considerable en su segunda edición de 1873-76, con la incorporación de dos volúmenes adicionales: A History of Indian and Eastern Architecture (vol.3) y la History of the Modern Styles (vol.4). En 1891 sufrió una tercera edición revisada póstuma, editada por R.Phene (vols. 1, 2), y R.Kerr (vols.4,5). La última reimpresión del manual de Fergusson fue en 2006, como facsímil de la edición de 1874. El manual también ha sido publicado bajo el título de Encyclopedia of World Architecture, from the Earliest to the Present Times, 3 vols., Nueva Deli, en 1998. La History of Architecture de Fergusson fue objeto asimismo de numerosas ediciones y reimpresiones en Estados Unidos durante el siglo XIX. Algunos de sus volúmenes también han sido objeto de impresiones independientes. La procedencia de las citas de las diferentes ediciones de la historia de la arquitectura de Fergusson aparecerán diferenciadas por el año de publicación, seguidas por el número del volumen y la página.

${ }^{10}$ El seguidor más obvio del manual de Fergusson, y el que suplantó su lugar como manual clásico de la historia de arquitectura en inglés es el de Sir Banister Fletcher, A History of Architecture, publicado por primera vez en 1896, y con numerosisimas reediciones, la última de ellas en el 2007.

11 Sobre las teorías de Fergusson al respecto véase su introducción al Illustrated Handbook of Architecture, xxvIvii y su An Historical Inquiry into the True Principles of Beauty in Art, more especially with Reference to Architecture, London, 1849. La cita procede del Handbook, 1855, I, xxvii.

${ }^{12}$ Cita en 1867, I, vii.

${ }^{13}$ Sus elogios no pueden ser más apasionados en este respecto: "not even the great Pharaonic era in Egypt, the age of Pericles in Greece, nor the great period of the Roman empire, will bear $\mathrm{cmparsion}$ with the $13^{\text {th }}$ century in Europe, whether we look to the extent of the buildings executed, their wonderful variety and constructive elegan$c e$, the daring imagination that concei- ved them, or the power of poetry and of lofty religious feelings that is expressed in every feature and in every part of them" (1855, II, 667).

$$
\begin{aligned}
& 14 \text { 1855, I, x. } \\
& 15 \text { 1855, I, 451-52. } \\
& { }^{16} 1855, \text { II, 2, 817. En el comen- }
\end{aligned}
$$
tario de que España era una mina desconocida de tesoros arquitectónicos, Fergusson se estaba haciendo eco de la guía sobre España de Richard Ford (ver n.18).

171855, II, 817 y 824 respectivamente.

18 La lista de estudios existentes del arte gótico español podría ser mucho más amplia, pero sólo se han mencionado aquellas cuyo conocimiento por parte de Fergusson está documentado: H. Flórez et al., España Sagrada: Theatro geographico-historico de la iglesia de España, 51 vols, Madrid, 1747-1879; A. Ponz, Viage de España, 18 vols., Madrid, 1772-1794; E. Llaguno y Amírola, Noticias de los arquitectos y arquitectura de España ... con notas, adiciones y documentos por D. Juan Agustín Cean-Bermudez, 4 vols., Madrid, 1829; R.Ford, A Handbook for travellers in Spain and Readers at Home, 3 vols. Londres, 1845 (reimp. Londres, 1966); S. E. Widdrington, Sketches in Spain During the Years 1829, 30, 31, \& 32, 2 vols., Londres, 1834; id., Spain and the Spaniards, 2 vols., Londres, 1844; N.A.Wells, The Picturesque Antiquities of Spain, Londres, 1846; G.A.Hoskins, Spain, as it is, Londres, 1851. Las ilustraciones de David Roberts en Thomas Roscoe, The Tourist in Spain and Morocco, 4 vols., Londres, 1835-38; las de Villaamil en G. Perez de Villaamil y P.de la Escosura, España Artística y Monumental, 3 vols, Paris, 1842-50; las de Laborde en A., Comte de Laborde, Voyage Pittoresque et Historique de l'Espagne, 4 vols., Paris, 1806-1820; J. Gailhabaud, Larchitecture du Vme au XVIIme siècle, 4 vols., Paris, 1858; N.M.J.Chapuy y P. Moret, Le moyen-âge pittoresque, Paris, 1837-40.

${ }^{19}$ Véanse por ejemplo los estudios de Daniel Ramée, Manuel de l'histoire générale de larchitecture chez tous les peoples et particulèrement de I'architecture en France, Paris, 1843;
Thomas Hope, An Historical Essay on Architecture, Londres, 1835; Carl Friedrich von Wiebeking, Von Dem Einfluss Der Baukunst Auf Das Allgemeine Wohl Und Die Civilisation. Nuremberg, 1818; y Franz Kugler, Jacob Burckhardt, and Wilhelm Lübke. Geschichte Der Baukunst. Stuttgart, 1856.

${ }^{20}$ Para más información sobre los historiadores españoles de la época de la ilustración véase Matilde Mateo, "Medievalism and Social Reform at the Academy of San Fernando in Spain (1759-1801)", Medievalism and the Academy, vol.1, Leslie J.Workman, KathleenVerduin and David Metzger (eds.), Studies in Medievalism, 9 (1997), 123-147. Dos importantes y excepcionales estudios que prestan gran atención a la arquitectura medieval son el de J.M.de Inclán Valdés, Apuntes para la historia de la arquitectura, Madrid, 1833, y el de J.Cáveda, Ensayo histórico sobre los diversos géneros de arquitectura empleados en España, Madrid, 1848. Fergusson, sin embargo, no conocía éstos últimos, ni tampoco los numerosos estudios de José Amador de los Ríos, Pedro de Madrazo, o la serie de Recuerdos y Bellezas de España, de F.J.Parcerisa, P.Piferrer, Pi y Margall, P. de Madrazo, y J.M.Quadrado, Madrid, 1839-65. De todas formas, ninguno de los estudios del romanticismo español sobre el gótico reunía las cualidades historiográficas que podrían haber satisfecho a Fergusson.

21 Sobre los comentarios de viajeros británicos sobre el arte medieval español véase Matilde Mateo Sevilla, La visión británica del arte medieval cristiano en España (siglos XVIII y XIX), Universidade de Santiago de Compostela, 1993, (microficha, Santiago de Compostela, 1994).

22 Respecto a la metodología de Fergusson y su confianza en la fotografía como fuente para la investigación histórica ver Elwall, op.cit. 396.

23 1855, 2, 819. Las plantas de las catedrales de Sevilla, Burgos y León aparecieron en el Viage de Ponz. La planta de la catedral de Sevilla aparecía también en F. de Torre Farfan, Fiestas de la Santa Iglesia Metropolitana y Patriarcal de Sevilla, Sevilla, 1671. Las plantas de S. Millán y los Templarios de Segovia en Gailhabaud, op.cit. 
24 1855, II, 818.

25 1855, II, 825.

${ }^{26}$ Citas sobre la catedral de Burgos en 1855, II, 826-28.

27 1855, II, 830.

${ }^{28}$ Ambas citas en 1855, II, 832.

29 1855, II, 837.

30 1855, II, 828.

31 1855, II, 839.

32 Fergusson advirtió al lector acerca de la apariencia engañosa de los edificios españoles ya que podrían ser edificios cristianos (1855, II, 842). Algunos ejemplos de edificios (románicos y góticos) en los que detectó infuencias "moras" son La Magdalena de Zamora, la colegiata de Toro, y las catedrales de Burgos y Toledo entre otros.

${ }_{3}$ 1855, II, 820-21.

34 Las ilustraciones de Villaamil procedían de La España Artística y Monumental (cit.supra). La atención prestada al mudéjar en esta publicación fue altamente novedosa, y ya fue tratada por mi en una comunicación "Christian versus Muslim in the 19th Century View of Medieval Spain: La España Artística y Monumental (1842-1850) and its Apology of the Christian Cultural Heritage ", presentada en el 36th International Congress on Medieval Studies, Kalamazoo (US), 3-6 May 2001. Por "moresco style" o "estilo moro" Fergusson se refería al mudéjar.

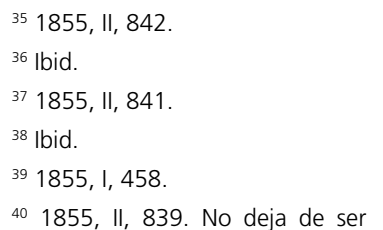
irónico que la ermita de Humanejos despertase tanta admiración y recibiera tan alto honor cuando los españoles la dejaron caer en la más absoluta ruina hasta su total desaparición. El dibujo de la ermita estaba tomado de La España Artística y Monumental.

${ }^{41} 1855$, II, 839 y 842 . La cita es de la página 842 .

42 lbid.

43 1855, II, 818.

${ }^{44}$ No está demostrado que Street emprendiese su estudio del gótico español espoleado por Fergusson aunque es altamente probable, ya que ambos se conocían personalmente y compartían editor, John Murray, y sobre todo porque Street, por confesión propia, utilizó para sus plantas la misma escala que las del manual de Fergusson. La contribución de Street al conocimiento del arte bajo medieval hispano fue fundamental y ya ha sido estudiada por mí en varias ocasiones. La última de ellas fue en una comunicación titulada G.E. Street's Some Account of Gothic Architecture in Spain: a Victorian Definition of the History of Spanish Medieval Art", CAA Conference, Chicago, 2001. Espero publicar en un futuro próximo un estudio monográfico sobre este tema, pero hasta entonces se puede encontrar más información y bibliografía en mi tesis doctoral, La visión británica.

45 1867,II, 122n, and 1865, I, v.

${ }^{46}$ Las relaciones entre Fergusson y Street fueron turbulentas debido, en gran medida, a sus opuestas posturas respecto al historicismo arquitectónico. Entre otros ejemplos de su enemistad destaca el ataque de Fergusson al proyecto más significativo de Street, las Law Courts de Londres. Este enfrentamiento fue público y estuvo también aleccionado porque no se había consultado con Fergusson al respecto, cuando él tenía oficialmente que dar el visto bueno (D.B.Brownlee, The Law Courts: the Architecture of George Edmund Street, Nueva York, 1984, 244-51).

${ }^{47}$ Street, op.cit. 445-6.

${ }^{48}$ Street, op.cit. 6.

${ }^{49}$ R. Kerr, op.cit., I, xiv.

${ }^{50}$ La mayoría de las ilustraciones nuevas son prestadas de Street y consisten en plantas, aunque también abundan los interiores. Para esta edición también utilizó el volumen dedicado a Asturias y León, de la serie Recuerdos y Bellezas de España, de J.M Quadrado y F.J. Parcerisa, publicado en Madrid en 1855, y los Monumentos Arquitectónicos de España, Madrid, 1859-95. Su estudio del gótico español se articuló en tres capítulos que comprendían una introducción general al tema, uno dedicado a la arquitectura religiosa, y el último a la civil, el cual, curiosamente, incluía los claustros. La consideración de la arquitectura monástica como arquitectura civil no deja de ser chocante, y sólo puede ser explicada por el criterio anacrónico de tener en cuenta no el carácter del edificio durante la Edad Media, sino en la época de Fergusson, en la que los monasterios habían sido afectados por disoluciones y desamortizaciones, con la consiguiente secularización de su carácter.

51 1867, II, 145.

52 1867, II, 146.

53 1867, II, 143, cit. en 144 .

54 1867, II, 121.

55 1867, II, 146.

${ }^{56}$ Street reconoció que pese a las influencias francesas y alemanas, los españoles habían producido "genuine Spanish Gothic churches" (op.cit. 440).

57 1867, II, 119.

58 1867, II, 119-120.

59 1876, II, 122.

601867, I, 354.

${ }^{61}$ La etnología era una ciencia en auge en este momento y cautivaba a gran parte de los eruditos británicos, como evidenció, entre otras cosas, la fundación, en 1843 de "The Ethnological Society". Para más información sobre el estado de la etnología en esta época ver T.K. Penniman, $A$ Hundred Years of Atnthropology, New York, 1936, esp cap. IV.

62 1867, I, 74. Fergusson defendió el carácter social de la arquitectura también en su primera edición (1855, II, 666).

631855 , I, lii.

64 1867, I, 73. Fergusson reconoció que su historia de la arquitectura arrojaba conclusiones diferentes a muchas de las propuestas por autores prestigiosos en los campos de la etnografía e historia. Defendió sus conclusiones con el argumento de que la arquitectura era mucho más fiable como fuente histórica que los documentos escritos. Para mayor información véanse sus argumentos en el prefacio a su segunda edición, especialmente pp. x-xii.

${ }^{65}$ Sobre la Leyenda Negra véanse J.Juderías, La Leyenda Negra. Estudios acerca del concepto de España en el extranjero, Madrid, 1954, y W.S. Maltby, The Black Legend in England, London, 1971.

${ }^{66} 1855$, II, 839 y History of Modern Styles, 1862, I, 132. 
${ }^{67}$ La acusación de que los españoles no habían aportado nada en el campo de la arquitectura fue un elemento tardío de la Leyenda Negra y no se constata hasta mediados del siglo XVIII. Es entonces cuando aparece en enciclopedias francesas, apoyada con ejemplos post-medievales -El Escorial, Palacio Real de Madrid, etc.- y más bien como comentario de pasada que como una teoría argumentada, como fue el caso de la entrada sobre "España" por M.. Robert y M. Masson de Morvilliers en la Encyclopedie Méthodique. Geographie Moderne, tom.1, Paris, 1782. El prejuicio de Fergusson contra España es probable que también se viese reforzado por la publicación de History of Civilization in England (Londres, 1857) de Henry Buckell, en la que la imagen negativa de España aparecía revitalizada con nuevos y pseudo científicos argumentos.

$$
\begin{aligned}
& { }^{68} 1867, \text { II, } 120 . \\
& { }^{69} 1867, \text { II, } 139-40 . \\
& { }^{70} 1867, \text { II, } 152 . \\
& { }^{71} \mathrm{Su} \text { explicación al respecto me- }
\end{aligned}
$$
rece ser citada en extenso: "On the whole, perhaps, we should not be far wrong in assuming that the Spaniards are among the least artistic people in Europe. Great things have been done in their country by foreigners, and they themselves have done creditable things in periods of great excitement, and under the pressure of foreign example; but in themselves they seem to have no innate love of Art, no real appreciation for its beauties and, when left to themselves, they care little for the expression of beauty in any of the forms in which Art has learned to embody itself. In Sculpture they have done very little; and in Architectural Art they certainly have not achieved success. Notwithstanding that they have a climate inviting to architectural display in every form, though they have the best of materials in infinite abundance, though they had wealth and learning, and were stimulated by the example of what had been done in their own country, and was doing by other nations, in spite of all this, they have fallen far short of what was effected either in Italy or France, and now seem to be utterly incapable of appreciating the excellences of Architectural Art, or of caring to enjoy them" (History of the Modern Styles, 1862, 158-59). Fergusson aquí se contradice con sus afirmaciones previas respecto al amor pasional que los españoles sentían, pese a su incapacidad creativa, por la arquitectura.

721865, I, 63.

73 1867, II. 121. La olla podrida es un plato típicamente español mencionado con frecuencia en las guías de viaje británicas del siglo XIX, consistente en un guiso con todo tipo de ingredientes.

${ }^{74}$ Su discusión acerca de las razas españolas es la siguiente: "If we knew who the Spaniards were we might be able to explain these phenomena [having a love of architecture but unable to produce one of their own], but we know so little of the ethnography of Spain that at present this source of information is not available. The term "iberian" hardly conveys a distinct idea to the mind. The first impulse is to say they must have been Turanian; but, if so, where are their tombs? Do any tumuli or dolmens or cromlechs exist in Spain? Or any traces of sepulchral rites or ancestral worship? If so, they certainly have not been described: and unless they exist or have existed, we are safe in asserting that no Turanian people lived in historic times in Spain. From history we know that the Phoenicians occupied the coastlines at the least all around the southern part of the Peninsula, and their settlement probably penetrated some way into the interior. The facility with which the Moors conquered and colonised the country, is in itself sufficient to prove that a people of cognate race had occupied the land long before they came there; but this harldy helps us, for neither the Phoenicians nor any of the Semitic races were ever builders, and we look in vain in Spain or at Carthage, or at Tyre or Sidon, for anyting to tell us what their architecture may have been. The Goths who invaded Spain in the beginning of the $5^{\text {th }}$ century must have been of Teutonic race, Aryans pure sang, for they have not left a building or a tradition of one, and they therefore can harldy have influenced the style of their successors in the Peninsula.
Even the Moors were scarcely an architectural people in the proper sense of the term. Their mosques were, so far as we know them, made up of fragments of classical temples arranged without art or design. Their palaces were ornamented with plaster work of the most admired complexity of design, coloured with the most exquisite harmony; but all this was the work of the ornamentalist, hardly of the architect. It was perfectly suited to the wants of a hardy race of mountaineers struggling for freedom against the invaders of their birthright. The Celtic element must have been the one wanting in this "olla podrida" of nations to fuse the whole together, and to give the arts that impulse which in Spain was always wanting. All the other elements they seem to have possessed, but the absence of this single one prevented them from attaining that unity which would enable us to follow their story with the same interest which we feel in tracing the development of the arts in France or England. Notwithstanding this, however, it must be confessed that the result in Spain is frequently grand, and even gorgeous, though never quite satisfactory." (1867, II, 120-21).

75 History of Modern Styles, 1862, I, 132). Véase también 1867, I, 57.

76 El criterio racial fue aplicado por Fergusson también a otros países. Uno de los ejemplos más llamativos al respecto es su periodización de la arquitectura india según criterios raciales de pureza aria (Thakurta, op.cit. , 898 y Mitter, op.cit. , 264-65).

77 Esta es la explicación completa en sus propias palabras: "It we knew more of the ethnic relations of the Moors, who conquered Spain in the $8^{\text {th }}$ century, we might perhaps be able to predicate whether it were possible for such dissimilar parents to produce a fertile hybrid. It seems certain, however, that the Moors did not belong to any Turanian race, or traces of their tombs would be found; but none such exist. Nor did they belong to any of the great building races, for during the whole of their sojourn in Spain they showed no constructive ability, no skill in arrangement of plans, and no desire for architectural magnificence. But they were a rich, luxurious, and refined 
people, possessing an innate knowledge of colour and an exquisite perception of the beauty of form and detail. They were, in fact, among the most perfect ornamentists we are acquainted with, but they were not architects. Had the inhabitants of Toledo from the $11^{\text {th }}$ century been French, or any Celtic race, the combination of their constructive skill with the taste in detail of the Moors could hardly have failed to produce the happiest results. As it was, after a few feeble efforts the style died out, but not without leaving some very remarkable speciments of architectural art, though on a small scale. They were also only in perishable plaster, which, though well suited to the style of the Moors, is a material which no architectural people ever would have employed."(1867, II, 153).

78 1867, II, 154-55.

$79 \mathrm{~J}$. Gwilt, An Encyclopaedia of Architecture, Historical, Theoretica, and Practical, ed. por W.Papworth, Londres, 1891, 965.

${ }^{80}$ Op.cit, 1890, xiv y 198. Sobre Moore véase Melissa Renn, "Charles Herbert Moore and the Teaching of Art at Harvard", The Last Ruskinians: Charles Eliot Norton, Charles Herbert Moore, and Their Circle, Cambridge, MA, 2007, 45-53; James Ackerman, "On the Study of Early Medieval Art at Harvard", Before and After the End of Time: Architecture and the Year 1000, New York, 2000, 101.

${ }^{81} \mathrm{Ibid} .297$ y 314.

${ }^{82}$ R. Sturgis, A History of Architecture, vol, III por A. L. Frothingham, 1915, 230.

${ }^{83}$ Bernard Bevan, History of Spanish Architecture (London: B.T. Batsford, 1938), xi. Este estudio tuvo una segunda impresión en Nueva York, en 1939. Para información sobre este estudio véase Harold E. Wethey, "History of Spanish Architecture by Bernard Bevan. Book Review," The Art Bulletin 22, no. 3 (1940), 178-181; John Bury, "Bernard Bevan (1903-1995), Historiador de la arquitectura española," Archivo español de arte 70, no. 278 (1997), 188-190; y la reciente traducción al español de su obra B. Bevan, Historia de la arquitectura española del Imperio Romano a la llustración, Madrid, 2012, especialmente el epílogo de Ana Esteban Maluenda, "En busca de Bernard Bevan. Historia de un libro singular", 357-376, y Fernando Vela Cossío, "Antes y después de Bevan. Historiografía de la arquitectura española," 343-356.

${ }^{84}$ J.H.Harvey, en su The Cathedrals of Spain (Londres, 1957) 8, y 38.

${ }^{85}$ Bevan, History of Spanish Architecture, xiv. Esta insistencia en el rastreo de influencias extranjeras no se limita al mundo anglosajón, y un ejemplo relativamente reciente de su vigencia en otras partes fue el congreso sobre Spanien und die Europäische Architektur der Gotick, Georg-August Universitat, Gottinguen, Febreo 4-6, 1994, (resumen por, Jan Klaus Philipp en Künstchronik, 1994, v. 47, 681-85). Para el caso francés se podría citar autores tan relevantes como H. Focillon, quien afirmó que el gótico español era una provincia francesa, y que el interpretar las variedades del gótico español en Castilla y Cataluña como algo propiamente español era un error, ya que su arquitectura pertenece no a España sino a occidente, quizás implicando que España no es occidental, y cuyos ligazón era primariamente con Francia (The Art of the West in the
Middle Ages: Romaesque and Gothic, Ithaca, NY, 1963, II, 59, ed. original en francés en Paris, 1938). Su compatriota, Elie Faure, era de la misma opinión, insistiendo, en típica vena Fergussiana, en la incapaz española para definir su alma de forma colectiva en la arquitectura (History of Art, Nueva York, 1937m 368, ed. original en francés de 1921). Los excesos de esta práctica han sido también denunciados con frecuencia. Uno de los primeros autores en reaccionar contra ella fue el español F.Chueca Goitia, en sus Invariantes castizos de la arquitectura española, Madrid, 1947; sobre la reacción de Chueca ante este problema véase mi artículo "The Form of Race: Architecture, Epistemology, and National Identity in Fernando Chueca Goitia's Invariantes castizos de la arquitectura española (1947)", Envisioning Others: Race, Color, and the Visual in Iberia and Latin-America, ed. por Pamela Patton, Brill Academic Publishers, 2016, 266-302. También es de destacar el reciente volumen editado por C. Robinson y L. Rouhi, Under the Influence: Questioning the Comparative in Medieval Castile, Leiden y Boston, 2005, en el que se ofrecen modelos metodológicos alternativos para estudio del arte español.

${ }^{86}$ Bevan, op, cit., 85.

${ }^{87}$ Me refiero a un argumento de corte orientalista como los definidos por E. Said en su clásico estudio Orientalism: Western Conceptions of the Orient, Nueva York, 1978. Véase también por este mismo autor Culture and Imperialism, Nueva York, 1994.

${ }^{88}$ N.Coldstream, Medieval Architecture, de la colección Oxford History of Art, Oxford, 2002. 